VIAL, Pelayo. "El derecho a confrontación con declaraciones de un juicio anulado en el marco del proceso penal".

Polit. crim. Vol. 6, No 12 (Diciembre 2011), Art. 6, pp. 448 - 473.

[http://www.politicacriminal.cl/Vol_06/n_12/Vol6N12A6.pdf]

\title{
EI derecho a confrontación con declaraciones de un juicio anulado en el marco del proceso penal
}

\author{
Pelayo Vial Campos \\ Profesor Destrezas de Litigación \\ pvial@,dpp.cl
}

\section{Resumen}

El nuevo proceso penal ha traído aparejada la inclusión de un modelo adversarial de juicio oral, en que por primera vez las partes son las encargadas de incorporar la evidencia al juicio. En ese contexto la examinación de los testigos, incluida su desacreditación, ha quedado entregada a los intervinientes a través del contraexamen, el que cumple el rol de depurar la prueba testimonial y pericial. Un de las fases del contraexamen es la impugnación de la credibilidad, etapa que requiere desarrollarse correctamente para que el nuevo modelo de juicio oral produzca evidencia de calidad para decidir el asunto sometido a juicio. El presente artículo analiza la posibilidad de usar durante el contraexamen, información que emane de un juicio anulado para desacreditar a los declarantes en un posterior juicio de reenvío.

\section{Palabras clave}

Principio de contradicción, juicio oral, contraexamen, desacreditación.

\begin{abstract}
The new criminal procedure has incorporated the adversarial model to the criminal trial, in which for the first time the parties are in charge of incorporating evidence in trial. In this context the witness examination, including their impeachment, has been handed over to the parties through cross-examination, its role to filter witness and expert testimony. One of the phases of the cross-examination is impeachment, which requires the correct development of this stage in order for the new model of public trial to produce precise evidence that will decide the litigious issue. This article discusses the possibility of using, during crossexamination, information from an annulled trial in order to discredit the witnesses' statements in a subsequent trial.
\end{abstract}

\section{Key words}

Principle of contradiction, trial, cross-examination, impeachment. 
VIAL, Pelayo. "El derecho a confrontación con declaraciones de un juicio anulado en el marco del proceso penal".

\section{Introducción.}

El proceso penal instaurado mediante la dictación del Código Procesal Penal del año 2000 (en adelante, CPP), consagra un modelo de juicio oral de carácter adversarial en el cual las partes deben aportan las pruebas y desacreditar a los testigos y peritos de la contraria mediante el contraexamen. ${ }^{1}$ En el nuevo modelo desaparecen las tachas de los testigos y nace el derecho de las partes a impugnar la credibilidad de testigos y peritos mediante su contrainterrogación.

Pues bien, el tema que se aborda en el presente artículo dice relación con la posibilidad de desacreditar a un testigo que declara en un segundo juicio oral y modifica su declaración sobre hechos debatidos importantes en relación a lo declarado sobre los mismos hechos, en un primer juicio oral anulado. En ese contexto y durante la etapa del contraexamen, ¿Es posible para el contraexaminador contrastar los dichos del testigo durante el segundo juicio oral con lo declarado por éste en el primer juicio anulado?

Al respecto existen dos posiciones, una que lo permite ${ }^{2}$ y otra que lo prohíbe. ${ }^{3}$ La posición que prohíbe desacreditar a un testigo citando su testimonio previo de un juicio anulado, parece basarse en concebir la nulidad recaída en el primer juicio oral como una sanción procesal que hace inutilizable todo lo cubierto por ella, incluso para efectos favorables a la parte que obtuvo esa declaración. ${ }^{4}$

${ }^{1}$ Cuando me refiero a testigo y peritos también incluyo en la problemática a la víctima, imputado, y a cualquier declarante que cambie su versión entre un primer juicio y los siguientes.

${ }^{2}$ Sentencia Tribunal Oral en lo Penal (en adelante, TOP) de Concepción de fecha 15/03/2011, Rit:477-2010. En la sentencia se hace mención a la diferencia entre los dichos de los testigos entre el primer y segundo juicio oral, ya que en el segundo juicio se aceptó preguntar a los testigos en referencia a lo declarado por ellos en el primero juicio oral. Asimismo, se acepta realizar la desacreditación en causa Rit: 454-2010 TOP de Concepción.

${ }^{3}$ Sentencia de Nulidad Corte de Apelaciones de Santiago, Recurso Nulidad, del 10 de Agosto de 2009, Rol $\mathrm{N}^{\circ} 1076-2009$, que en su Considerando $5^{\circ}$ señala: "Que el alcance de las facultades del defensor, en general, y la posibilidad de formular preguntas al testigo en el marco del artículo 309 inciso primero ya citado, deben interpretarse de acuerdo a los principios y normas que regulan el proceso penal. Al respecto, cabe señalar que los artículos 332 y 334 del citado cuerpo legal permiten demostrar las contradicciones de un testigo solo con declaraciones anteriores prestadas ante el juez, fiscal o la policía. Claramente, la invocación de declaraciones anteriores prestadas en un juicio oral declarado nulo no se enmarcan dentro de ninguna de las normas supuestamente infringidas.”. En los mismo términos causa Rit: 387-08 del TOP de Concepción y en momentos que la defensora a cargo se aprestaba a realizar preguntas para desacreditar a la víctima respecto de su cambio de versión, fue impedida de hacerlo por el Tribunal, advertida de la siguiente forma por el juez presidente:"Muy bien. Le recuerdo que los juicios anteriores si es que hubiesen existido, y las declaraciones prestadas no son materia de este juicio. Lo que es materia de este juicio son los hechos de la acusación y es en base a ello las preguntas que Ud. tiene que formular, no en relación a lo que hubiese declarado supuestamente en audiencias anteriores.".

${ }^{4}$ Nuestra Excelentísima Corte Suprema en sentencia de nulidad de fecha 24/12/07, rol 5415-07 y resolviendo acerca de prueba ofrecida por el recurrente emanada de un proceso anulado señala en el considerando $26^{\circ}$ : "Que, no obsta a lo anterior, la prueba producida en la audiencia del cuatro del actual para acreditar la causal de la letra b) del artículo 373 del Código Procesal Penal, pues no se dará valor a los referidos antecedentes porque de la documental proporcionada queda en evidencia que se ha pretendido introducir al debate elementos vinculados a un juicio íntegramente anulado, de modo tal que por vía consecuencial, la prueba ofrecida carece de toda validez, estando vedado a este tribunal referirse a argumentaciones que formaron parte del anulado procedimiento.", fuente http://www.poderjudicial.cl La interpretación dada por nuestra 
Polit. crim. Vol. 6, № 12 (Diciembre 2011), Art. 6, pp. 448 - 473.

[http://www.politicacriminal.cl/Vol_06/n_12/Vol6N12A6.pdf]

La situación anterior, muy probablemente sería inexplicable para cualquier ciudadano común; esto es que un testigo, que declare en un mismo proceso ante diferentes jueces sobre los mismos hechos, cambie su versión en el segundo juicio y la parte que se ve perjudicada por el cambio de versión sea impedida de demostrar este cambio a los jueces del segundo juicio oral que deben valorar la credibilidad del testigo.

En términos jurídicos, la situación descrita no parece ser compatible con el delito de falso testimonio ya que de entenderse como inexistente todo lo sucedido en el primer juicio, difícil sería configurar este delito, asimismo sería incompatible con la causal del recurso de revisión contemplada en la letra c) del artículo 473 del Código Procesal Penal.

Pero más allá de los aspectos legales, el sentido común nos dice que quien cambia su versión sobre los hechos que declara debe ser castigado en su credibilidad. Para lo anterior, que es de toda lógica, los jueces deben conocer ambas versiones.

Pues bien, en el contexto reseñado y volviendo al tema propuesto, ¿Es válido limitar el material de impugnación a los litigantes hasta impedir que un testigo sea desacreditado durante su contraexamen con sus declaraciones contradictorias realizadas en un juicio anterior anulado?

El presente trabajo intentará señalar los argumentos por los cuales el contraexamen no puede limitarse hasta el extremo antes señalado, he intentará explicar su rol en el establecimiento de la verdad en un proceso acusatorio-adversarial.

Por último, es también un objetivo de este artículo advertir acerca del escaso desarrollo que ha tenido el contrainterrogatorio en nuestra práctica y doctrina, lo que debe ser corregido, a efecto que éste pueda cumplir su rol en el proceso.

\section{El contraexamen y su importancia en los procedimientos adversariales en relación a la verdad.}

El contraexamen ha sido definido como la gran herramienta legal jamás inventada para el descubrimiento de la verdad. ${ }^{56}$

En la tradición legal de Estados Unidos este derecho es tan esencial que fue incorporado en la Sexta enmienda de la Constitución Norteamericana -cláusula de confrontación- que en

Excelentísima Corte Suprema, parece ser que la prueba emanada de un juicio anulado no sería admisible como prueba sustantiva de cargo, pero nada se dice sobre su uso para posibles fines de impugnación.

5 POZNER, Larry S. y DODD, Roger, Cross Examination Science and Techniques, Virginia: The Michie Company, 1993, p. 2, citan a John Henry Wigmore, y su manual Wigmore on Evidence, también citado por: DAMASKA, Mirjan, "Presentation of Evidence and Fact-Finding Precision", University of Pennsylvania Law Review, Vol. 123, p. 1106 y MacCARTHY, Terence, MacCarthy on Cross-Examination, American Bar Association, 2007, p. vi.

${ }^{6}$ Davis v. Alaska, 415 U.S. 308 (1974), "El contraexamen es el principal medio por el cual la credibilidad de un testigo y la verdad de su testimonio son cotejados (testeados)" Traducción libre de: "Cross-examination is the principal means by which the believability of a witness and the truth of his testimony are tested.". 
VIAL, Pelayo. "El derecho a confrontación con declaraciones de un juicio anulado en el marco del proceso penal".

su parte pertinente señala: "En toda causa criminal, el acusado gozará del derecho de ser juzgado públicamente y... ser confrontado (careado) con los testigos en su contra; que se obligue a comparecer a los testigos en su favor...". Este derecho se hace extensivo a los procesos civiles a través del concepto del debido proceso. ${ }^{7}$

Siguiendo la conocida decisión de la Corte Suprema Norteamericana Crawford v. Washington, ${ }^{8}$ podemos entender que este concepto se remonta al derecho romano ${ }^{9}$ y su fuente inmediata está en el common law inglés, en que tradicionalmente la forma en que los testigos prestaban declaración difería de cómo los testigos prestaban declaración en el "continental civil law". A saber, se señala que la tradición del common law es que los testigos comparezcan personalmente al tribunal y que su declaración sea sujeta al testeo de carácter adversarial, mientras que en la tradición del civil law las examinaciones eran en privado ante un oficial judicial. ${ }^{10}$ En la decisión citada se señala además que el derecho inglés fue acogiendo ciertas prácticas continentales como lo era recabar declaraciones previas al juicio ${ }^{11}$-las que sin perjuicio que su objetivo inicial no era para ser usadas en juicio- se usaron como evidencia en los procesos.

El punto de quiebre de esta tendencia fueron algunos juicios políticos de los siglos 16 y 17 específicamente se cita el seguido en contra de Sir Walter Raleigh en que el acusado fue condenado a muerte y una de las pruebas habría sido una carta de un cómplice. ${ }^{12}$ Lo anterior en opinión de uno de los jueces, fue que la justicia en Inglaterra nunca había sido

\footnotetext{
${ }^{7}$ Armes v. Pierce Governor Co., 121 Ind. App. 566, 573, 101 N.E.2d 199, 203 (1951), (Court of Appeals of Indiana) "El derecho a contrainterrogar testigos que están bajo juramento no es una regla de procedimiento o evidencia. Es fundamental para un debido proceso, y no puede, a menos que se renuncie, ser negado por ningún Juez (examinador de los hechos), cualquier corte, o tribunal administrativo". Traducción libre de: "The right to cross-examine witnesses under oath is not a rule of procedure or evidence. It is fundamental to due process, and cannot, unless waived, be denied by any [**204] trier of facts, any court, or administrative tribunal'. Se citan además las siguientes decisiones: Henry v. State (1925), 196 Ind. 14, 146 N.E. 822; Alford v. U.S. (1931), 282 U.S. 687, 75 L. Ed. 624, 51 S. Ct. 218.

${ }^{8}$ Crawford v. Washington, 541 U.S. 36,(2004).

${ }^{9}$ Hechos 25/16: "A esto respondí que no es costumbre de los romanos entregar alguno a la muerte antes que el acusado tenga delante a sus acusadores y pueda defenderse de la acusación", versión de la Biblia, revisado 1960, Casiodoro de Reina (1569) Cipriano de Valera (1602). Citado U.S. Supreme Court Coy v. Iowa, 487 U.S. 1012 (1988): “..There are indications that a right of confrontation existed under Roman law. The Roman Governor Festus, discussing the proper treatment of his prisoner, Paul, stated: "It is not the manner of the Romans to deliver any man up to die before the accused has met his accusers face to face, and has been given a chance to defend himself against the [487 U.S. 1012, 1016] charges.". Acts 25:16. It has been argued that a form of the right of confrontation was recognized in England well before the right to jury trial. Pollitt, The Right of Confrontation: Its History and Modern Dress, 8 J. Pub. L. 381, 384-387 (1959)". Por último, en la misma decisión se señala que el derecho a confrontación se reconoció en Inglaterra antes que el derecho a juicio por jurado.

${ }^{10}$ Crawford v. Washington, 541 U.S. 36 (2004). “... English common law has long differed from continental civil law in regard to the manner in which witnesses give testimony in criminal trials. The common-law tradition is one of live testimony in court subject to adversarial testing, while the civil law condones examination in private by judicial officers. See $3 \mathrm{~W}$. Blackstone, Commentaries on the Laws of England 373374 (1768)."

${ }^{11}$ Crawford v. Washington, 541 U.S. 36 (2004)., "Justice of the peace or others officials examined suspects and witnesses before trial".

${ }^{12}$ El acusado Sir Walter Raleigh alegó que el cómplice que había escrito la carta y declarado previamente había mentido para salvarse, exigiendo que éste compareciera a la audiencia, lo que fue rechazado.
} 


\section{Polit. crim. Vol. 6, No 12 (Diciembre 2011), Art. 6, pp. 448 - 473. [http://www.politicacriminal.cl/Vol_06/n_12/Vol6N12A6.pdf]}

tan degradada y lastimada. Esta práctica llevó a que con posterioridad se realizaran cambios estatutarios para respetar el derecho a confrontación.

Como se ve, el contraexamen en la tradición del common law se establece como un elemento central del modelo adversarial del proceso, ${ }^{13}$ y tiene una tradición de muchos siglos.

Por otra parte cabe señalar que ambos modelos, el angloamericano y el continental, discuten acerca de la verdad en el proceso. La Corte Suprema de EE. UU. ha señalado que un objetivo fundamental de un juicio criminal es la búsqueda de la verdad. ${ }^{14} 15$

La doctrina procesal emanada del derecho continental también discute acerca de verdad y proceso penal, centrando parte importante de esa discusión en las funciones y atribuciones del juez. Parte de la doctrina postula que al entregar más facultades al juez éste será capaz de encontrar la verdad de lo declarado, ${ }^{16}{ }^{17}$ descartando sin mayor análisis que cada vez que el juez abandona sus tareas decisorias ve se afectada seriamente su imparcialidad. ${ }^{18}$

${ }^{13}$ Sobre el origen del sistema adversarial se puede consultar, LANGBEIN, John H., The Origins of Adversary Criminal Trial, EE.UU.: Oxford University Press, Reprinted 2005, quien establece un vínculo entre el sistema adversarial y el permitir el desarrollo de los abogados defensores mediante el "Treason Trial Act of 1696" en Inglaterra.

${ }^{14}$ Tehan v. Shott, 382 U.S. 406 (1966) “...The basic purpose of a trial is the determination of truth"; Estes v. Texas, 381 U.S. 532 (1965) "..Court proceedings are held for the solemn purpose of endeavoring to ascertain the truth which is the sine qua non of a fair trial. Over the centuries Anglo-American courts have devised careful safeguards by rule and otherwise to protect and facilitate the performance of this high function..". Las Reglas Federales de Evidencia de EE. UU. (en adelante, FRE) también buscan la verdad, FRE 102 "Purpose and Construction: These rules shall be constructed to secure fairness in administration, ... to the end that the truth may be ascertained...'En el mismo sentido Regla 102 de Evidencia de Puerto Rico. LaFAVE, Wayne R., ISRAEL, Jerold H. y KING, Nancy J., Criminal Procedure, EE.UU.: Thomson West, 4 ${ }^{\mathrm{a}}$ ed., p. 26, se señalan que varios elementos del sistema de justicia criminal están diseñados a efecto de descubrir la verdad, tales como, entregar suficiente capacidad a los investigadores para descubrir los crímenes y sus autores, facultades a la policía y fiscales, en cuanto al proceso se establece que su forma adversarial contribuye a ello, así como limitar ciertas actuaciones engañosas de los adversarios, reglas de evidencia, eliminar jurados parciales a través de su descalificación, descubrimiento de prueba, etc.

${ }^{15}$ En la tradición norteamericana esta preocupación tiene dos elementos (i) El descubrimiento de los delitos (ii) La determinación de quién lo cometió y quien no lo cometió ver LaFAVE/ISRAEL/KING, Criminal Procedure, cit. nota $\mathrm{n}^{\circ}$ 14, p. 26. En el mismo sentido Recurso Nulidad C. Sup. rol 4164-09 de fecha 01/09/09, considerando $9^{\circ}$ "...sin que otro poder del mismo Estado pueda avocarse a esa función, y a la forma de posicionarse el juez frente al conflicto, de modo que no medie compromiso con los litigantes o el asunto, desde que en todo proceso penal aparece comprometido el interés público de la comunidad en el esclarecimiento de los sucesos y el castigo de los delitos, como también la absolución del inocente;...”.

${ }^{16}$ Uno de los exponentes de esta doctrina es Michelle Taruffo, en diversas publicaciones. Al respecto puede consultarse TARUFFO, Michelle, "Investigación Judicial y Producción de Prueba por las Partes" en: VERA ÁLVAREZ, Nicolás (coord.), La Prueba, Artículos y Conferencias, Santiago: Editorial Metropolitana, pp. 80 y ss. Bajo esta misma lógica se justificaba el procedimiento inquisitivo penal.

${ }^{17}$ BOVINO, Alberto, "Ingeniería de la Verdad. Procedimiento Penal Comparado", artículo publicado en http://derechopenalonline.com, en nota 4 el autor señala que entre nosotros se asume sin mayor análisis que el tribunal inquisitivo es la única forma existente de averiguación de la verdad.

${ }^{18}$ Acerca de esto último vale la pena destacar que nuestra Excelentísima Corte Suprema ha señalado que la posición pasiva del juez es una salvaguarda a su imparcialidad ver sentencia de nulidad C. Sup. de fecha 1/09/09 rol 4164-09, considerando 14: "Que las dudas del tribunal oral deben ser satisfechas por las partes,.... Esta fórmula de llevar adelante la audiencia, es una manifestación del principio contradictorio que rige en el nuevo sistema penal y que constituye un elemento del derecho a defensa y, asimismo, del debido 
VIAL, Pelayo. "El derecho a confrontación con declaraciones de un juicio anulado en el marco del proceso penal".

Pues bien, nadie duda que el modelo adversarial de proceso penal del common law opta por un juez más pasivo respecto al ingreso de la evidencia al juicio -un árbitro silencioso- sin embargo el juez en el proceso penal adversarial no sólo puede preguntar a los testigos mucho más allá de lo prescrito en nuestro artículo 329 inc. $5^{\circ}$ del Código Procesal Penal, sino que además puede llamar testigos, ${ }^{19}$ cuestión que regularmente no realizan para no comprometer su imparcialidad. $^{20} 21$

Sin perjuicio de lo interesante que puede resultar la discusión acerca de los poderes del juez y la búsqueda de la verdad en el proceso, lo que interesa en este artículo es una etapa previa y que dice relación con establecer mecanismos de interrogación que entreguen material de calidad al juzgador para que evalúe la credibilidad, exactitud y confiabilidad del relato del testigo, ${ }^{22}$ en ello nos ayuda un análisis profundo del contraexamen.

Sabemos que en la tradición continental europea el análisis de la verdad y proceso se han dirigido a discutir qué tipo de verdad buscar, omitiendo una discusión de fondo respecto a la actividad probatoria ${ }^{23}$ y procesal que aseguren que la prueba sea de calidad, lo que

proceso, por cuanto la neutralidad del tribunal se asegura y garantiza a través del veto a su iniciativa probatoria.". En el mismo sentido en sentencia de nulidad C. Sup. de fecha 12/11/08 rol 4954-08, considerando $9^{\circ}$.

${ }^{19}$ FRE 614 Calling and Interrogation of Witnesses by Court (a) Calling by court. The court may, on its own motion or at the suggestion of a party, call witnesses, and all parties are entitled to cross-examine witnesses thus called. (b) Interrogation by court. The court may interrogate witnesses, whether called by itself or by a party. (c) Objections to the calling of witnesses by the court or to interrogation by it may be made at the time or at the next available opportunity when the jury is not present. MAUET, Thomas y WOLFSON, Warren D., Trial Evidence, EE.UU.: Aspen Publishers, $3^{\mathrm{a}}$ ed., p. 12: al referirse a esta regla señala que las restricciones al juez es que las preguntas deben ser conducidas en forma imparcial, no debe demostrar hostilidad a ninguna de las partes, y debe enviar un mensaje claro a los jurados que él no cree en testigos claves o en una parte determinada.

${ }^{20}$ DAMASKA, Mirjan, "The Uncertain Fate of Evidentiary Transplants: Anglo-American and Continental Experiments", The American Journal of Comparative Law, Vol 45, №4 (otoño 1997), analizando la posibilidad de entregar un rol más activo al juez en relación a la prueba en el sistema Anglo Americano, p. 849 nos señala que nunca se ha clarificado el límite preciso del juez en la examinación (incorporación) de la evidencia: "It is true that the precise limits of legitimate judicial involvement with the examination of evidence have never been clearly defined". En este sentido y frente a la posibilidad de entregar mayores funciones al momento de interrogar a los testigo el autor indica que para ser un buen interrogador quien interroga debe conoce acerca de la materia (los hecho), para satisfacer este requisito una posibilidad sería que el juez contara con un expediente pero esta posibilidad en palabras de Damaska sería torcer la tradición del common law referente a qué se entiende por el concepto de imparcialidad judicial: "But such step would seriously strain the traditional common law understanding of judicial impartiality".

${ }^{21}$ En todo caso esta facultad debe ser analizada en un sistema de juicio por jurado en que existe una clara división de labores, un juez determina que evidencia es admisible, el jurado determina los hechos y los abogados presentan las evidencias; en palabras de Mauet el juez decide qué evidencia pueden presentar los abogados al jurado; el jurado decide qué valor (peso) tiene la evidencia si la tiene, MAUET/WOLFSON, Trial Evidence, cit. nota $\mathrm{n}^{\circ} 19$, p. 9, traducción libre “...the judge decides what evidence the lawyers can present to the jury; the jury decides what weight, if any, that evidences should receive.".

${ }^{22}$ DAMASKA, Mirjan, "Truth \& Its Rivals: Evidence Reform and the Goals of Evidence Law", University of California, Hastings College of Law Hastings Law Journal (January 1998), p. 1: se señala que uno de los supuestos de la práctica del derecho es que la verdad puede descubrirse y que la precisión en el establecimiento de los hechos constituye una condición previa a una decisión justa.

${ }^{23}$ BOVINO, Alberto, "Juicio y Verdad en el Procedimiento Penal”, en: AA. VV., Estudios sobre Justicia Penal, libro homenaje al profesor Julio Maier. Buenos Aires: Editoriales del Puerto, 2005, p. 227, nos advierte sobre la falta de análisis de la actividad probatoria en nuestra tradición continental señalando: "Uno 


\section{Polit. crim. Vol. 6, No 12 (Diciembre 2011), Art. 6, pp. 448 - 473. [http://www.politicacriminal.cl/Vol_06/n_12/Vol6N12A6.pdf]}

explica la casi nula regulación de reglas de evidencia en nuestro sistema y el poco desarrollo de los elementos de control de calidad de la prueba como el contraexamen.

En este punto del análisis cabe profundizar y preguntarse: ¿Por qué tanta regulación y desarrollo del contraexamen y sus etapas en el sistema anglosajón?. El primer motivo ya ha sido esbozado y dice relación con que el contraexamen es el elemento que materializa la adversariedad en el proceso, estructural esencial del proceso anglosajón, lo que se abordará en un momento posterior.

El segundo motivo y en lo que dice relación con la incorporación de la evidencia, se funda en que las reglas del contraexamen toman en consideración una visión de la existencia humana. La percepción, incluida la habilidad para reconocer a una persona, es poco confiable, pero sobre valorada. La memoria se equivoca. ${ }^{24}$ Los testigos honestos son sugestionables y comenten errores. Otros son corruptos y mienten o ocultan la verdad. El prejuicio, el interés o tener una motivación determinada, son rasgos humanos que afectan la veracidad de lo declarado, sea en forma intencional o no. Cuando una persona relata dos historias diferentes de un mismo evento, su credibilidad puede cuestionarse. La apariencia física es valorada al momento de dar credibilidad a un testimonio. Algunas técnicas de persuasión e interrogación generan error. ${ }^{25} 26$

de los problemas que, a nuestro juicio, complica el análisis respecto cómo opera el deber de determinar la verdad se vincula con el hecho de que las consecuencias de tal actividad no depende exclusivamente del concepto de verdad que asumamos, sino, además y especialmente, de la función que le asignemos a la actividad procesal en general, y a la actividad probatoria en particular. En nuestra tradición jurídica, el tema de la prueba se estudia de manera inadecuada, pues sólo se estudian -si es que se hace- las reglas vigentes que organizan su incorporación válida al proceso y, por otra parte y en menor medida, las reglas mediante las cuales deben ser valorados los elementos de convicción".

${ }^{24} \mathrm{Al}$ respecto cabe visitar la página web http://www.innocenceproject.org y consultar el documento "Convicted by Juries, Exonerated by Science: Case Studies in the Use of DNA Evidence to Establish Innocence after Trial". U.S. Department of Justice, Office of Justice Programs, National Institute of Justice, 1996. Este último estudio identifica y analiza 28 casos en que personas condenadas son exoneradas demostrando su inocencia a través de pruebas de $\mathrm{ADN}$, la causal de error más frecuente es la errónea identificación. Asimismo, en la página web señalada se pueden consultar las causales más frecuentes de error que llevaron a condenas equivocadas. En el Reino Unido existe un organismo para revisar posibles errores judiciales en materia penal, "Criminal Cases Review Commission", ver: http://www.ccrc.gov.uk. Sobre confiabilidad de los testimonios se puede consultar LOFTUS, Elizabeth F., Eyewitness Testimony, Boston: Harvard University Press, $4^{\mathrm{a}}$ ed., 2002. También IBADE EROSTARDE, Izaskun, Psicología del Testimonio, España: Erein Editoriales, 2004.

${ }^{25}$ Casi literal de MAUET/WOLFSON, Trial Evidence, cit. nota ${ }^{\circ} 19$, p. 371.

${ }^{26}$ Sobre el reconocimiento de errores en condenar a personas inocentes se puede consultar United States $v$. Burns, [2001] 1 S.C.R. 283, 2001 SCC 7 en http://www.canadalegal.com, decisión de la Corte Suprema de Canadá en que se señala: "El sistema legal (judicial) debe vivir con la posibilidad de error... desde algunos años ayudado por los alcances de las ciencias forense, incluidas las pruebas de ADN, las cortes y el gobierno en este país y en otras partes han debido admitir varias condenas equivocadas ..a pesar de todas las salvaguardas realizadas para la protección de los inocentes". Traducción libre de: "Legal systems have to live with the possibility of error. The unique feature of capital punishment is that it puts beyond recall the possibility of correction. In recent years, aided by the advances in the forensic sciences, including DNA testing, the courts and governments in this country and elsewhere have come to acknowledge a number of instances of wrongful convictions for murder despite all of the careful safeguards put in place for the protection of the innocent.". Sobre el rol de la defensa y los errores en el sistema de justicia cabe consultar KENNEDY, Jerome P., "Writing the wrongs: The role of defence counsel in wrongful convictions A 
VIAL, Pelayo. "El derecho a confrontación con declaraciones de un juicio anulado en el marco del proceso penal".

La teoría del contraexamen ${ }^{27}$ está dirigida a obtener toda la verdad de lo que conoce un testigo acerca de los hechos. ${ }^{28}$ Normalmente un testigo sólo descubre en el interrogatorio de quien lo presenta parte de los hechos, no la totalidad de ellos. Los hechos que permanecen ocultos o no se develan pueden ser de dos clases (i) las circunstancias que rodean las materias objeto del testimonio y (ii) los hechos que disminuyen la credibilidad del testigo.

La primera de las circunstancias puede suceder por dos razones; primero: que la parte que declara sea parcial en favor de quien lo presenta o segundo: porque el abogado que lo presenta nunca preguntará sobre hechos o circunstancias que pueden ser contrarios a su teoría.

Por otra parte, las circunstancias o hechos que desacreditan a quien declara en general no son develados espontáneamente por éste, ya que ningún testigo quiere que se desacredite su versión de los hechos.

Pues bien, una vez asumido que lo anterior sucede con los testigos es que debemos crear instituciones que logren filtrar la prueba en forma confiable, en la especie el contraexamen, pero no cualquiera sino uno que faculte al abogado que contrainterroga a descubrir todo lo que pueda favorecer a su cliente, permitiendo entonces escudriñar en lo declarado por el testigo en el examen directo, revelando las falsedades, exageraciones, parcialidades y otras divergencias de la verdad. ${ }^{29}$

commentary", Canadian Journal of Criminology and Criminal Justice/La Revue canadienne de criminologie et de justice pénale v.46, n. 2 (2004).

${ }_{27}$ En esta parte se sigue lo expuesto por BOYLL, Jeffrey A., "Witness Explanations During CrossExamination: a Rule of Evidence Examined", Indiana Law Journal (spring 1982).

${ }^{28}$ Lo que en nuestro derecho tiene sustento legal en normas tales como el artículo 298 del CPP:"Deber de comparecer y Declarar: Toda persona que no se encontrare legalmente exceptuada tendrá la obligación de concurrir al llamamiento judicial practicado con el fin de prestar declaración testimonial; de declarar la verdad sobre lo que se le preguntare y de no ocultar hechos, circunstancias o elementos acerca del contenido de su declaración.”. Esta norma está en los mismos términos en el artículo 38 de la Ley 19.668, y artículo 284 del Proyecto de Código Procesal Civil.

${ }^{29}$ En el sistema anglosajón, el reconocimiento a que el contraexamen es capaz de descubrir las inexactitudes, equivocaciones, errores o falsedades de lo declarado por los testigos, se acepta desde hace dos siglos, ver Jackson v. Kniffen, 2 Johns. 31, 35 (N.Y.1806): "Qué (como) a menudo es que el testimonio que al inicio aparece conclusivo e irrefutable, es completamente fragmentado por el contraexamen, que el testigo termina probando más en contra de sí que de quien lo presentó", traducción libre de: "How often is testimony which, when first delivered, appears conclusive and irrefragable, entirely frittered away by [cross-examination]-so much so, that a witness well sifted not infrequently proves more against than in favor of the party that produces him.". En el mismo sentido Perry v. Leake, 488 U.S. 272, 283 n.7 (1989) "La antigua herramienta del proceso de juicio para descubrir la verdad es el derecho al contraexamen. Por los pasados dos siglos, la política del sistema angloamericano de evidencia ha sido considerar la necesidad del testeo mediante el contraexamen como un rasgo vital de la ley". Traducción libre de: "The age-old tool ferreting out in the trial process is the right to cross-examination. For two centuries past, the policy of the Anglo-American system of evidence has been to regard the necessity of testing by cross-examination as a vital feature of the law"; y Ohio v. Roberts, 448 U.S. 56, 71 (1980): "el propósito principal del contraexamen es: para desafiar si el declarante sinceramente estaba diciendo lo que creía era la verdad, si el declarante percibió con precisión y si recuerda el asunto que relata, y si el declarante transmitía en el lenguaje expresado correctamente lo que quería decir". Traducción libre de: “...the principal purpose of cross-examination: to challenge "whether the declarant was sincerely telling what he believed to be the truth, whether the declarant accurately perceived 
Polit. crim. Vol. 6, № 12 (Diciembre 2011), Art. 6, pp. 448 - 473.

[http://www.politicacriminal.cl/Vol_06/n_12/Vol6N12A6.pdf]

\subsection{Elementos del Contraexamen para el cumplimiento de sus objetivos.}

Una vez establecido que el contraexamen tiene un rol central en el establecimiento de la verdad debemos analizar qué elementos debe tener para cumplir tan trascendente misión, lo que se abordará en lo sucesivo.

\subsubsection{Uso de preguntas sugestivas.}

El primer elemento que es necesario para que el contraexamen cumpla su objetivo, es permitir el uso de preguntas sugestivas ${ }^{30}{ }^{31}$ para quien contraexamina a un testigo hostil, ${ }^{32}$ entendiendo por estas últimas aquellas que sugieren al testigo la respuesta deseada, usualmente preguntando al testigo si ciertos hechos son verdad y forzándolo a que responda negando o reconociendo los hechos. Este mecanismo hace que el abogado que desarrolla el contraexamen destaque los hechos que demuestran falencias en la versión del testigo que éste regularmente no develará en forma voluntaria, pudiendo entonces desacreditar al testigo o su testimonio.

El uso de preguntas sugestivas en el examen directo con un testigo que le es favorable a quien examina hace que la información que otorga el testigo sea poco confiable, ya que el abogado a través de la sugestión puede incorporar hechos útiles a su teoría del caso pero alejados de la realidad, los que no serán negados por el testigo "amigable". Este peligro desaparece en el contraexamen ya que normalmente el testigo será hostil a quien lo contrainterrogar lo que regularmente hace que éste incluso puede negar los hechos tal cual sucedieron aun ante preguntas sugestivas, ${ }^{33}$ única forma entonces de poder desacreditarlo. ${ }^{34}$

and remembered the matter he related, and whether the declarant's intended meaning is adequately conveyed by the language he employed...".

${ }^{30}$ Ohio v. Roberts, 448 U.S. 56 (1980) se señala: "su presentación estaba repleta de preguntas sugestivas la principal herramienta y característica del contraexamen", traducción libre de: "His presentation was replete with leading questions, the principal tool and hallmark of cross-examination". Esta decisión fue anulada por la opinión del Juez Antonin Scalia en Crawford v. Washington, 541 U.S. 36 (2004) pero no en lo referente a lo que constituye un correcto contraexamen. Ver McCARTHY, Terence F., MacCarthy on CrossExamination, EE.UU.: ABA Publishing, 2007, p 85.

${ }^{31}$ El permitir las preguntas sugestivas en el ámbito procesal civil lo propone CAROCA, Alex, "Recuperación de la Importancia de la Prueba en un Modelo Procesal Civil Oral” en: DE LA OLIVA SANTOS, Andrés y PALOMO VÉLEZ, Diego (coords.), Proceso Civil, Hacia una Nueva Justicia Civil, Santiago: Editorial Jurídica de Chile, 2007, p. 371: "Estableciendo que ambas partes van a contar con sus respectivos abogados, la regla que sigue es prohibir en el interrogatorio de los testigos y peritos propios las preguntas sugestivas o inductivas. Esta prohibición no debe extenderse a los contrainterrogatorios, posibilitando un test de veracidad de los testigos y peritos que contribuye a que la calidad de la información que emana de los juicios orales sea superior...".

${ }^{32}$ La hostilidad del testigo es la que ha consagrado el contraexamen a través de preguntas sugestivas en EE.UU., incluso cuando un testigo se inclina en favor de quien lo contraexamina, en algunas jurisdicciones se restringe el uso de preguntas sugestivas. "However, when it appears that the witness is biased in the crossexaminer s favor and likely to yield to suggestions of leading questions, the judge in many jurisdictions may restrain the asking of them", STRONG, John W., McCormick on Evidence, St. Paul: West Group, student edition, $5^{\mathrm{a}}$ ed., 1999, p. 36.

${ }^{33}$ El peligro de contaminar la versión del testigo en un interrogatorio directo se puede graficar con el siguiente ejemplo; el abogado pregunta: “Sr. xxx, la noche estaba clara?”. El peligro está en que el testigo "amigable” piense: "en realidad la noche no estaba muy clara, pero para ganar este juicio mi abogado requiere que le diga 
VIAL, Pelayo. "El derecho a confrontación con declaraciones de un juicio anulado en el marco del proceso penal".

En síntesis, el uso de preguntas sugestivas debe permitirse en el contraexamen con los testigo hostiles a quién contrainterroga ya que éstos estarán dispuestos a negar cualquier afirmación que se les proponga incluso aquellas que entreguen la verdadera versión de los hechos, elementos que solo pueden aparecer en el juicio a través de la pregunta sugestiva.

\subsubsection{Evitar respuestas evasivas que escondan o no develen hechos importantes.}

Un segundo elemento que requiere el contraexamen para cumplir su rol es que el testigo ante una pregunta clara, precisa y pertinente, éste la conteste. Cuando un testigo a través de respuestas evasivas evita contestar derechamente una pregunta clara, precisa y pertinente dirigida a materializar los derechos y obligaciones del testigo contenidos en los artículos 298 y 309 del CPP, está realizando una actividad procesal no permitida según lo dispuesto en la primera de las normas antes citadas.

Lo que suele suceder en la práctica es que en muchas ocasiones los testigos evitan contestar una pregunta que los desacredita, a través de una respuesta evasiva, pero que entrega hechos pertinentes que en general los tribunales aceptan.

Profundizando lo señalado, si el testigo a través de respuestas evasiva lo que hace es ocultar circunstancias o elementos de su declaración, entonces debe ser conminado a contestar - $\mathrm{O}$ a lo menos restar absoluta credibilidad a todo su testimonio- ya que el testigo no sólo debe concurrir al llamamiento judicial, sino que debe responder toda la verdad sobre lo que se le pregunte sin ocultar hechos o circunstancias que lo desacrediten a él o su versión de los hechos.

Es efectivo que el testigo puede explicar sus dichos, pero eso debe ser en una etapa procesal distinta a la del contraexamen conocida como el re-directo que en nuestro sistema está consagrado en el artículo 329 inc. $5^{\circ}$ del Código Procesal Penal.

La obligación de contestar todo lo que se le pregunte a un testigo no debe ser algo tan extraño a nuestra tradición, ya que en el ámbito civil y referente a la declaración de partes, -absolución de posiciones- si ésta no concurre, o se niega a colaborar o entrega respuestas evasivas, la sanción puede llegar a ser que el juez de por efectivo los hechos materia de la absolución. $^{35}$

El comprender que durante el contraexamen el testigo debe contestar derechamente lo que se le pregunta y luego en el re-directo puede explicar parte de sus respuesta, le da una lógica, en el proceso adversarial a cada una de las etapa de la interrogación de los testigos en un juicio.

que estaba clara, entonces contestaré que la noche era clara”. Este peligro desaparece con el testigo hostil, sin importar la fase en que se lo interrogue.

34 BOVINO, "Juicio y Verdad", cit. nota ${ }^{\circ}$ 23, p. 238, citando a Wigmore, señala: "Si el testigo es hostil a quien lo interroga no hay razón alguna para prohibir las preguntas sugestivas desde que no hay peligro de que se sugieran falsedades con éxito".

${ }^{35} \mathrm{Al}$ respecto ver art. 52 Ley 19.968.- que Crea los Tribunales de Familia, art $454 \mathrm{~N}^{\mathrm{o}} 3$ inc. $1^{\circ}$ de la Ley 20.087.- que sustituye procedimiento laboral y art. 294 del Proyecto de Código Procesal Civil. 


\section{Polit. crim. Vol. 6, No 12 (Diciembre 2011), Art. 6, pp. 448 - 473. [http://www.politicacriminal.cl/Vol_06/n_12/Vol6N12A6.pdf]}

\subsubsection{Realizar los Interrogatorios con pleno conocimiento.}

Para que un interrogatorio sea efectivo se requiere que quien interroga conozca la mayor cantidad de hechos ya sean positivos o negativos de quien declara y sobre las materias que ha declarado el testigo. ${ }^{36}$

Por lo anterior, no sólo es necesario permitir durante al contraexamen el uso de preguntas sugestivas y obligar a que los testigos contesten todas las preguntas pertinentes, útiles y adecuadas, sino que además quien interroga debe tener el conocimiento suficiente para que pueda develar los hechos omitidos por el declarante. ${ }^{37}$ Como observa Damaska ${ }^{38}$ quizás esta sea una de las mayores diferencias entre el sistema anglosajón y continental; el rol de los abogados en la investigación de los hechos. Mientras para los abogados del sistema anglosajón es una obligación investigar a los testigos, para los abogados del sistema continentales puede ser visto como una falta a las reglas de conducta profesional.

Este último, requisito, sin duda requiere de transformaciones mayores de nuestro sistema procesal ya que éste tendrá que otorgar los mecanismos para que los intervinientes puedan acceder a los testigos ${ }^{39}$ e interrogarlos con anterioridad al juicio, cuestión que en principio en nuestro proceso no es posible en sede judicial.

Resumiendo entonces, se puede establecer que el contraexamen en la tradición del common law es un elemento central en la búsqueda de la verdad ${ }^{40} \mathrm{y}$ en nuestro sistema una vez eliminadas las tachas y establecido un modelo de juicio oral contradictorio -único que satisface la cláusula del debido proceso ${ }^{41}$ en que cada parte es dueña de su prueba- el

\footnotetext{
${ }^{36}$ DAMASKA, "The Uncertain Fate", cit. nota ${ }^{\circ} 20$, p. 850, señala que para que el proceso de interrogación sea efectivo quien interroga debe estar familiarizado con la materia sobre la cual interrogue, "...to remind the reader that the interrogation process- to be effective- requires the questioner to be familiar with the subject matter of inquiry.".

${ }^{37}$ En este sentido nuestra Excelentísima Corte Suprema en recurso de nulidad rol: 2345-05, de fecha 13/07/05 reconoce en su considerando $5^{\circ}$ que el derecho a defensa se satisface no solo a través del contraexamen si no que con el tiempo para su debida preparación: "QUINTO: Que, en otro orden de ideas, el sentenciador incurre en un error al suponer que el derecho de defensa del imputado se salvaguarda simplemente con la facultad que tiene para contrainterrogar a los testigos del querellante en la audiencia de estilo. Su derecho a defensa pasa también por tener la oportunidad y tiempo suficiente para su debida preparación. A este respecto es pertinente traer a colación que el artículo 309 del Código Procesal Penal..., derecho que sólo podrá ejercer después de averiguar con anticipación todo cuanto concierna al testigo propuesto una vez que conozca con precisión su identidad y halla previsto las preguntas que le podrá formular en el juicio.".

${ }^{38}$ DAMASKA, "The Uncertain Fate", cit. nota n 20, p. 847.

${ }^{39}$ Sobre el acceso a la evidencia éste se regula en los artículos 188 y 320 del CPP. Sobre la posibilidad de acceder a realizar pericias psicológicas a víctimas de delitos sexuales, durante la vigencia de reforma procesal penal se ha accedido en sede judicial ante lo cual el Ministerio Público ha deducido recursos de protección que se han rechazado, siendo ratificados por la Excelentísima Corte Suprema, ver recurso de protección C. Sup., Rol 5025-05, de fecha 27/10/05.

40 Así también parece entenderlo en el ámbito continental BOVINO, Alberto, "Ingeniería de la Verdad", cit. nota $\mathrm{n}^{\circ} 17$, p. 4 , quien señala que el contraexamen no es sólo una consecuencia del derecho a defensa, ya que se otorga a ambas partes para que cumpla su rol en la búsqueda de la verdad. Por lo anterior es que no basta señalar que el contraexamen deriva del derecho a defensa, salvo que este último derecho se entienda para las dos partes en conflicto.

${ }^{41}$ Al respecto DUCE, Mauricio, RIEGO, Mauricio, y MARÍN, Felipe, "Reforma a los Procesos Civiles Orales: Consideraciones desde el debido proceso y calidad de información", en: CABEZÓN P., Andrea
} 
VIAL, Pelayo. "El derecho a confrontación con declaraciones de un juicio anulado en el marco del proceso penal".

contraexamen tiene una doble función; (i) materializar el proceso de depuración de prueba, primer paso para encontrar la verdad y (ii) materializar el principio de contradicción. ${ }^{42}$

Por último y en relación a los objetivos señalados, el contraexamen debe estar dotado de los elementos necesarios para cumplir su rol. Al efecto, debe permitirse el uso de preguntas sugestivas, evitar que a través de respuestas evasivas no se develen todos los hechos importantes para la resolución del asunto y que los intervinientes estén debidamente informados para interrogar desde el conocimiento pleno de los hechos.

\section{Prohibición de tachas y sistema de impugnación.}

Como se dijo, nuestro Código Procesal Penal junto con eliminar el sistema de tachas de los testigos $^{43}$ otorgan a las parte la posibilidad de dirigir preguntas para demostrar su falta de credibilidad, idoneidad o imparcialidad. ${ }^{44}$ Sin perjuicio de ello no se establecen debidamente los mecanismos procesales para materializar este derecho, -siendo insuficiente lo prescrito en los artículos 309 y 318 del Código Procesal Penal- lo que a la

(Coord.), Justicia Civil: Perspectiva para una Reforma en América Latina, Santiago: CEJA, 2008, p. 35 señalan al referirse al juicio oral que para que éste cumpla con la cláusula del debido proceso debe ser una audiencia oral, pública y contradictoria.

${ }^{42}$ En el actual desarrollo de la doctrina procesal podemos señalar que un proceso “...se estructura en base a dos posiciones distintas y enfrentadas y un juez que, situado neutralmente por encima de ellas, presencia y dirige una posible controversia entre quienes ocupen esas posiciones". PALOMO VÉLEZ, Diego, citando a De Oliva Santos. "Proceso Civil Oral ¿Qué modelo de Juez Requiere?”, en: DE LA OLIVA/PALOMO, Proceso Civil, cit. nota $\mathrm{n}^{\circ}$ 31, p. 246. MONTERO AROCA, Juan, "Principio Acusatorio y Prueba en el Proceso Penal. Inutilidad Jurídica de un eslogan político", en: GÓMEZ COLOMER, Juan Luis (coord.), Prueba y Proceso Penal, Valencia: Tirant lo Blanch, 2008, p. 22 señala: "El llamado proceso acusatorio sí es un verdadero proceso, por cuanto en él existen realmente un juez tercero, independiente e imparcial y dos partes enfrentadas entre sí en pie de igualdad y con plena contradicción". NOGUEIRA ALCALA, Humberto, El debido proceso en la constitución y el sistema interamericano, Santiago: editorial Librotecnia, 2007, p. 65 señala: "El derecho a la defensa contradictoria de las partes en un proceso, mediante la oportunidad de alegar y probar sus derechos e interés". El carácter de adversarial o contradictorio del proceso ha sido reconocido por nuestra Excelentísima Corte Suprema a propósito de acoger un recurso de nulidad deducido por infracción de garantías constitucionales en atención al uso excesivo de la facultad de preguntar - art. 329 inc. $5^{\circ} \mathrm{CPP}-$ por parte de un Magistrado de Tribunal Oral, sentencia de nulidad de fecha 01/09/09 Rol 4164-09, considerando $10^{\circ}$ : “...deberá serlo con la mayor prudencia posible, recordando los jueces siempre como coto, que es función exclusiva de las partes incorporar la evidencia en juicio, y mantenerse ajenos al debate adversarial entre ellas". Ver también sentencias de nulidad C. Sup. Rol 3795-06 de fecha 26/09/08 considerando $11^{\circ}$, Rol 6631-07 de fecha 30/01/08 considerandos $6^{\circ}$ y $7^{\circ}$, Rol 4954-08 considerando $9^{\circ}$.

${ }^{43}$ Entendido por este último concepto: “...el medio procesal para hacer valer la inhabilidad que afecta a los testigos", según se señala en MATURANA M., Cristián, Los Medios de Prueba, separata de la Universidad de Chile, Facultad de Derecho, 1996, p. 85.

${ }^{44}$ En el mismo sentido el proyecto de Código Procesal Civil: “Artículo 325.- Interrogatorio de los testigos, peritos y de las partes. ...No se podrá formular tachas a los testigos y a los peritos, sin perjuicio de poder formularle las preguntas pertinentes en relación con su imparcialidad e idoneidad, y poder hacer las observaciones que estimen oportunas respecto de sus circunstancias personales y de la veracidad de sus manifestaciones en su alegato al término de la audiencia de juicio"; y la Ley 19.968 que crea los Tribunales de Familia: "Artículo 40.-Declaración de testigos. En el procedimiento de familia no existirán testigos inhábiles. Sin perjuicio de ello, las partes podrán dirigir al testigo preguntas tendientes a demostrar su credibilidad o falta de ella, la existencia de vínculos con alguna de las partes que afectaren o pudieren afectar su imparcialidad, o algún otro defecto de idoneidad.". 
Polit. crim. Vol. 6, № 12 (Diciembre 2011), Art. 6, pp. 448 - 473.

[http://www.politicacriminal.cl/Vol_06/n_12/Vol6N12A6.pdf]

luz de la libertad probatoria, y valoración de la prueba según la sana crítica ${ }^{45}$, puede producir un retroceso en relación al procedimiento penal reglado por el antiguo código de procedimiento penal a la hora de establecer prueba de calidad.

\subsection{Sistema Comparado.}

En el sistema norteamericano para materializar el derecho de las partes a demostrar la falta de credibilidad de los testigos se establece el impeachment, ${ }^{46}$ que entre nosotros se conoce como desacreditación o impugnación de testigos. En el ámbito de la litigación el impeachment se define como: "Técnica del contraexamen que desacredita al testigo o su testimonio. Su propósito es simple: mostrar al juez (jurado) que este testigo o parte de su testimonio no puede ser creíble.", 47 también se señala que cuando el contraexamen ataca la credibilidad del testigo se llama impeachment. ${ }^{48}$

La regla federal de evidencia de los EE.UU. 607 se refiere a quien puede desacreditar. ${ }^{49}$ Esta regla establece que la credibilidad del testigo puede ser atacada por cualquier parte incluso por la que lo presenta. La regla en comento viene a corregir un regla del derecho común que impedía impugnar a un testigo propio -voucher rule-. Esta regla fue enmendada argumentándose que las partes no son absolutamente libres para elegir sus testigos, ${ }^{50}$ e impedir que quien presenta un testigo no pueda desacreditarlos, deja a esa parte a merced del testigo y el adversario. Si una parte llamaba a un testigo y éste miente beneficiando a la contraparte mediante perjurio el adversario no lo impugnará, mientras que la parte que lo había llamado no podía impugnarlo, pero si el testigo declara la verdad, entonces el adversario puede impugnarlo. ${ }^{51}$

\footnotetext{
${ }^{45}$ El establecimiento del sistema de libre convicción o sana crítica racional queda de manifiesto en los artículo $1^{\circ}$ y 297 del CPP, como lo señala LOPEZ MASLE, Julián y HORVITZ, María Inés, Derecho Procesal Penal Chileno, T. II, Santiago: Ed. Jurídica de Chile, 2004, p. 151.

46 "Impeachment: 1.-Reconvención, tacha, desdoro. 2.- Acusación pública; la acción de pedir cuentas.", VELÁSQUEZ, Un diccionario Nuevo con pronunciación de los idiomas Inglés y español, Nueva York: Appleton/Century/Crofts, 1967.

${ }^{47}$ MAUET, Thomas, Trial Techniques, New York: Aspen Publishers, $6^{\circ}$ Ed, 2002, p. 273: "Impeachment is a cross-examination technique that discredits the witness or his testimony. Its purpose is simple: show the jury that this witness, or this part of his testimony, cannot be believed".

${ }^{48}$ MAUET, Trial Techniques, cit. nota ${ }^{\circ}$ 47, p. 376.

${ }^{49}$ FRE, 607 "Quién puede desacreditar: La credibilidad de un testigo puede ser atacada por cualquier parte, incluyendo la parte que llamó al testigo", traducción libre de FRE Rule 607: "Who May Impeach: The credibility of a witness may be attacked by any party, including the party calling the witness".

${ }^{50}$ U.S. Supreme Court, Chambers v. Mississippi, 410 U.S. 284 (1973). "En los juicios criminales modernos, los imputados rara vez están capacitados para seleccionar a sus testigos; ellos deben tomarlo donde los encuentren". Traducción libre de: "But in modern criminal trials, defendants are rarely able to select their witnesses: they must take them where they find them".

${ }^{51}$ CHIESA, Ernesto, Tratado de Derecho Probatorio, T. I., EE.UU.: Publicaciones JTS, Reimpresión, 2005, p. 394. En el mismo sentido en MAUET/WOLFSON, Trial Evidence, cit. nota ${ }^{\circ} 19$, p. 377, que señala que la ley reconoce que existen ocasiones en que una parte debe llamar testigos que son menos que ideales, pero información relevante debe ser deducida de un testigo renuente a declarar por quien lo presenta. El ataque de la credibilidad de un testigo por parte de quien lo presenta puede ser parte de la búsqueda de los hechos relevantes y efectivos o confiables.
} 
VIAL, Pelayo. "El derecho a confrontación con declaraciones de un juicio anulado en el marco del proceso penal".

Las reglas federales de evidencia y la práctica reconocen siete métodos o capítulos de desacreditación: ${ }^{52}$

1.- Parcialidad, interés y motivación.

2.-Declaraciones previas inconsistentes FRE 613.

3.- Hechos contradictorios.

4.- Condenas anteriores FRE 609.

5.- Reputación de poco creíble o sincero FRE 608(a).

6.- Conducta probada de poco sincero FRE 608(b).

7.- Mediante la desacreditación entre lo dicho y lo escrito en algún texto o tratado ampliamente reconocido FRE 803 (18).

Como se ve no todos los motivos y formas de desacreditación están expresamente regulados, pero se han desarrollado en la práctica y jurisprudencia. ${ }^{53}$

Existen además ciertos requisitos generales para poder desacreditar a un testigo que son a saber: La desacreditación requiere buena fe, este requisito está basado en la regla de conducta profesional que previene que un abogado no debe aludir a ningún asunto que sabe no relevante o que no será sostenido con evidencia admisible. ${ }^{54}$ Como señala Mauet ningún abogado puede levantar ningún tema de desacreditación si no sabe que el asunto es relevante (pertinente) y admisible. Si el juez tiene dudas acerca de la desacreditación debe preguntar acerca de las bases en que el abogado basa sus preguntas y de no tenerlas no las debe permitir. Un ejemplo ayuda a clarificar el concepto, el interrogador no puede preguntar si el testigo había bebido tres copas antes de ser testigo del choque, de no tener evidencia que lo anterior efectivamente había sucedido. ${ }^{55}$

\footnotetext{
${ }^{52}$ La regla 44(B) de evidencia de Puerto Rico incluye seis medios de impugnación en forma meramente ilustrativo. El Código de Evidencia de California en su regla 780 incluye las siguientes: (a) His demeanor while testifying and the manner in which he testifies.(b) The character of his testimony.(c) The extent of his capacity to perceive, to recollect, or to communicate any matter about which he testifies.(d) The extent of his opportunity to perceive any matter about which he testifies.(e) His character for honesty or veracity or their opposites.(f) The existence or nonexistence of a bias, interest, or other motive.(g) A statement previously made by him that is consistent with his testimony at the hearing.(h) A statement made by him that is inconsistent with any part of his testimony at the hearing.(i) The existence or nonexistence of any fact testified to by him.(j) His attitude toward the action in which he testifies or toward the giving of testimony.(k) His admission of untruthfulness.

${ }^{53}$ La Corte Suprema de EE.UU. en Davis v. Alaska, 415 U.S. 308, 315 (1974) estableció que el derecho a desacreditar a un testigo es un componente importante del derecho a confrontar a los testigos contenido en la VI Enmienda en relación a la IV de la Constitución. En los mismos términos Delaware v. Van Arsdall, 475 U.S. 673 (1986) en que se señala que la Corte al no permitir desacreditar al testigo por ser parcial infringió el derecho a confrontar. (VI Enmienda): “...While the trial court's denial of respondent's opportunity to impeach the prosecution witness for bias violated respondent's rights under the Confrontation Clause...". En el primer caso Davis v. Alaska, no se permitió a la defensa hacer preguntas a un testigo clave del fiscal (Green) para demostrar su parcialidad, ya que el testigo había sido sospechoso en el mismo caso y tenía antecedentes previos como menor que lo tenían con una suerte de beneficio (probation). En este caso se resolvió que el derecho a confrontar del imputado debe preferirse al del testigo (Green) a no ser incomodado (avergonzado u ofendido) con el descubrimiento de los antecedentes anteriores.

${ }^{54}$ Rule of Ethics. Model Rules 3.4: "A lawyer shall not ... allude to any matter that the lawyer does not reasonably believe is relevant or that will not be supported by admissible evidence".

${ }^{55}$ MAUET/WOLFSON, Trial Evidence, cit. nota n ${ }^{\circ} 19$, p. 380.
} 
El segundo requisito dice relación con la confrontación o "warning question" la actual regla 613 (b) que señala que al testigo debe otorgársele la oportunidad de explicar o negar y asimismo a la contraparte una oportunidad para interrogar antes de incorporar evidencia extrínseca de veracidad de la declaración previa. ${ }^{56}$ Como tercer requisito la impugnación debe ser relevante al asunto discutido en el caso y la credibilidad del testigo, sin lo cual puede admitirse ${ }^{57}$ y debe resolverse la dicotomía entre colateral y no colateral. ${ }^{58}$

Respecto a la confrontación en un caso criminal por interés, motivo o parcialidad la Corte Suprema de EE.UU. ha señalado que se viola la sexta enmienda constitucional cuando un juez prohíbe desacreditar a una víctima de violación con preguntas acerca del posible motivo por el cual éste imputa el hecho. ${ }^{59}$

Respecto a la desacreditación con declaraciones inconsistentes, estas pueden ser orales o escritas, lo central es que la declaración previa sea inconsistente con el testimonio del testigo en el juicio. Por otra parte, no es necesario que la inconsistencia sea directamente contradictoria, basta que la declaración inconsistente u omisión tenga una tendencia razonable a desacreditar el testimonio del testigo.

Como se observa del somero análisis en el sistema adversarial de EE.UU. en este se ha desarrollado la desacreditación como integrante del contraexamen, constituyéndose en un efectivo mecanismo de depuración de la evidencia presentada en juicio.

\subsection{En nuestro sistema.}

Por ahora solo cabe señalar que en nuestro proceso penal el sistema de impugnación antigua tacha de testigos- tiene consagración legal en normas como los artículos, 309, 318, en relación a los artículos 298, 329, 332 y 334 todos del Código Procesal Penal y a nivel de tratados internacionales en normas como los artículos 14 ap. $3^{\circ}$ letra e) y 8 ap. $2^{\circ}$ letra f) del Pacto Internacional de Derecho Civiles y Políticos y la Convención Americana sobre Derechos Humanos respectivamente.

Sin perjuicio de ello no existe un desarrollo jurisprudencial o efectivo de los mecanismos de desacreditación. Un ejemplo -además de la problemática que motiva este trabajopuede clarificar la afirmación anterior; dada la normativa de los artículos 332 y 334 del Código Procesal Penal en algunos casos los tribunales impiden que quién contraexamina

\footnotetext{
${ }^{56}$ MAUET/WOLFSON, Trial Evidence, cit. nota, ${ }^{\circ} 19, \mathrm{p} .381$.

${ }^{57}$ MAUET/WOLFSON, Trial Evidence, cit. nota ${ }^{\circ} 19$, p. 382, señala como ejemplo que si el testigo señala en el examen directo que el auto viajaba a $70 \mathrm{mph}$, y durante el contraexamen se le pregunta si él le señaló a la policía que el auto se desplazaba entre 65 a 70, la diferencia entre 65 y 70 es insignificante. Una objeción basada en las bases generales de pertinencia o en la FRE 403 señalando que la evidencia está produciendo confusión o pérdida de tiempo debe ser aceptada.

${ }^{58}$ La definición de colateral es: "Si la materia de desacreditación puede ser debidamente incorporada al juicio para el propósito más allá de contradecir el testimonio del testigo, no es colateral. Si la materia de desacreditación es admisible sólo para contradecir el testimonio del testigo es entonces colateral". Se ha establecido que ciertas categorías de desacreditación son siempre no colaterales. Tales como parcialidad, interés, motivación y antecedentes anteriores, otros asuntos dependen de cada caso. MAUET/WOLFSON, Trial Evidence, cit. nota, $\mathrm{n}^{\circ} 19$, p. 382 y383.

${ }^{59}$ Olden v. Kentucky, 488 U.S. 227 (1988).
} 
VIAL, Pelayo. "El derecho a confrontación con declaraciones de un juicio anulado en el marco del proceso penal".

contraste los dichos del testigo o perito con declaraciones previas inconsistentes o contradictorias que no se hayan prestado ante el fiscal o el Juez de Garantía, ${ }^{60}$ lo que unido al rol pasivo de los tribunales respecto al ingreso de la evidencia puede producir una perturbación en el sistema. Así el, testigo podría contradecir todos los hechos previamente declarados, impedirse al abogado que contraexamina demostrar las contradicciones, y el tribunal fallar en ignorancia de la existencia de las contradicciones.

El simple ejemplo anterior, sumado al análisis del sistema comparado denuncian que es imprescindible un mayor desarrollo de instituciones tales como el contraexamen en su fase de la impugnación por los operadores del sistema, como asimismo un mayor desarrollo de éste en el ámbito doctrinario y jurisprudencial en base a las normas antes citadas para asegurar evidencia de calidad, lo que parece en principio la única respuesta posible a la problemática que convoca este trabajo. ${ }^{61}$

\section{Acerca de los efectos del recurso de nulidad.}

Pues bien, una vez analizado brevemente el sistema de impugnación de credibilidad de los testigos y su escasa regulación en nuestro sistema podemos intentar volver al tema propuesto para argumentar una solución más acorde con la posibilidad de nutrir a nuestro sistema con adecuados mecanismo de control de calidad de la prueba. Previo a ello debemos referirnos a los efectos del recurso de nulidad.

\subsection{De los efectos del recurso de nulidad.}

Los recursos constituyen un medio de impugnación de las resoluciones judiciales, que tradicionalmente han sido vistos como medios de subsanar los errores que puede adolecer una resolución judicial. Asimismo, es necesario señalar que quien interpone un recurso necesita ser la parte agraviada por la resolución que se recurre. El agravio, a su turno, es una condición para su ejercicio pero asimismo un límite a la competencia específica del tribunal superior para resolver el recurso conforme a lo prescrito en el artículo 360 del Código Procesal Penal con la excepción contemplada en el artículo 379 inciso $2^{\circ}$ del mismo cuerpo legal.

\footnotetext{
${ }^{60}$ Suponga usted el siguiente caso: El fiscal acusa por el delito de robo en lugar habitado por la hipótesis de fuerza (fractura de la puerta de ingreso), la defensa alega que es un hurto, en atención a que el acta de fuerza señala: “...que revisada la propiedad no se encontró signo de fuerza en la puerta de ingreso”. El policía que declara en la audiencia de juicio oral declara que él confeccionó el acta de fuerza. Asimismo, declara que él en el acta de fuerza consignó fuerza en la puerta de acceso a la casa. Esta información es absolutamente contradictoria con lo consignado en el acta de fuerza que el mismo policía había confeccionado y que se encuentra adjuntada en los antecedentes recopilados por el Ministerio Público durante la etapa de investigación. Nadie duda que esta información deba ser conocida por el Tribunal Oral en lo Penal para los efectos de la credibilidad de ese testigo según lo dispuesto en el artículo 309 del CPP. El acta de fuerza es uno de aquellos registros de la investigación que debe levantar la policía y que según algunos no podría ser leído en el juicio oral en virtud de lo prescrito en el artículo 334 del CPP.

61 Por último, cabe indicar que los mecanismos destinados a asegurar prueba de calidad no pasan por restablecer el antiguo sistema de tachas que parece absolutamente ineficiente al efecto. Al respecto cabe señalar que es inefectivo para desacreditar a un testigo el solo probar que en la especie se configura una causa de tacha -como el parentesco- ya que puede ser que a pesar de ello el testigo sea fidedigno en su relato, en atención que para configurar la tacha parece no necesario probar, porque la causal invocada en el caso concreto convierte al testigo en poco creíble.
} 


\section{Polit. crim. Vol. 6, No 12 (Diciembre 2011), Art. 6, pp. 448 - 473. [http://www.politicacriminal.cl/Vol_06/n_12/Vol6N12A6.pdf]}

De lo anterior, la doctrina procesal ha elaborado el concepto de cosa juzgada parcial, para referirse a las partes de la sentencia que no causan agravio o, sencillamente, no resultan afectadas por el recurso interpuesto. En palabras de Maier:

"la existencia eventual de un recurso sólo provoca, en principio, el nuevo examen del caso sólo en relación al agravio (error o injusticia) expuesto en él y, de la misma manera, limita el conocimiento del tribunal ad quem. Como se concibe la cosa juzgada parcial, el fallo recurrido queda a firme en todo aquello que no constituye materia del agravio expuesto en el recurso. Así se logra la seguridad jurídica del recurrente quien conoce que, salvo la facultad de otros intervinientes para recurrir, su recurso fijará el thema decidendum y no atribuirá al tribunal del recurso una posibilidad cognoscitiva más amplia que la puesta por él en juego". ${ }^{62}$

En síntesis entonces, en razón que el perjuicio opera como límite de la competencia para resolver un recurso de nulidad, en doctrina existe el concepto de nulidad parcial, situación reconocida en nuestro Código Procesal Penal como se concluye de la lectura de los artículos 360,385 y $386 .^{63}$

A mayor abundamiento, cabe señalar que de la relación entre las disposiciones anteriormente citadas, nuestros tribunales superiores coligen, de manera aparentemente pacífica, que cuando les corresponde dictar sentencia de reemplazo acogiendo un recurso de nulidad en los casos de una decisión injusta (como, por ejemplo, el caso de condenar a una persona cuando los hechos imputados no constituyen tipo penal alguno) previstos por

\footnotetext{
${ }^{62}$ MAIER, Julio, Derecho Procesal Penal, Buenos Aires: Editores del Puerto s.r.1., 2002, p. 593.

${ }^{63}$ Sobre los efectos del recurso de nulidad y el artículo 360 del CPP, se puede consultar BARRIENTOS PARDO, Ignacio, "Prohibición de la reforma in peius y la realización de Nuevo Juicio", Revista de Estudios de la Justicia $\mathrm{N}^{\circ} 9$ (2007), pp. 175-201. En él se postula que en virtud del principio de reformatio in peius, para el caso que el primer juicio sea recurrido sólo por el condenado, en el segundo juicio no se puede establecer una condena más gravosa que la primera. En el sentido señalado MAIER, Julio, Función Normativa de la Nulidad, Buenos Aires: Ediciones DePalma, 1980, pp. 141-142, en que señala que la nulidad es una categoría que no hace desaparecer el acto, cita un caso en argentina en que una sentencia viciada aceptada por el acusador solo recurrida por el acusado, la Cam. Crim y Corr de la ciudad de Bs Aires resuelve equivocadamente en su opinión ya que se decidió que el fallo de reenvió es inexorable. La doctrina antes expuesta fue acogida por la Corte de Apelaciones de Antofagasta en sentencia de nulidad de fecha 3/09/09, Rol: 227-09, acogiendo un recurso de nulidad señaló en el considerando $7^{\circ}$ respecto a la posibilidad de un segundo fallo condenatorio "...el principio de la reformatio in peius y que consiste en la prohibición de extender el efecto de la decisión de los recursos a cuestiones no planteadas por ellos o más allá de los límites solicitados, consagrado dogmáticamente en el artículo 360 del Código Procesal Penal....En consecuencia, frente a la posibilidad de una nueva sentencia condenatoria, el Tribunal Oral en lo Penal deberá tener presente las limitaciones de no agravar la pena impuesta, según la sentencia que se anula.”. Esta doctrina fue revocada por la Excelentísima Corte Suprema en Sentencia de fecha 02.09.10 recurso de queja deducido por el Ministerio Público en contra de la Iltma. Corte de Apelaciones de Antofagasta rol: 4012-10, señalándose que los Sr. Ministros de la Iltma. Corte de Apelaciones de Antofagasta cometieron falta o abuso grave al acoger un recurso de nulidad deducido por la defensa ordenado al Tribunal Oral en lo Penal de Antofagasta que debía conocer del segundo juicio oral quedaba limitado en la posible sanción penal en no establecer una más gravosa. La Excelentísima Corte Suprema respecto a este último aspecto señaló: "QUINTO: Que lo propio acontece al delimitar las facultades del tribunal oral, restringiendo las prerrogativas de que están investidos para, entre otras materias y en el evento de dictar un fallo condenatorio, determinar el quantum de la pena, impidiéndole sancionar al imputado a una pena más gravosa a aquella determinada en el juicio anulado, en todo caso, inferior a la requerida por el Ministerio Público.”.
} 
VIAL, Pelayo. "El derecho a confrontación con declaraciones de un juicio anulado en el marco del proceso penal".

el artículo 385 del Código Procesal Penal, no pueden reformar la sentencia en perjuicio del recurrente ni extender el efecto de su decisión a cuestiones diversas de las planteadas por el recurrente.

\subsection{Nulidad, invalidación y juicio de reenvío.}

Fernando De La Rua al tratar el tema de la sentencia anulada nos señala: "la nulidad no elimina el acto, solo lo priva de sus efectos normales o inmediatos pero subsiste para otros; entre ellos obra como limite al futuro fallo...". ${ }^{64}$

Por otra parte, Claria Olmedo destacan que el juicio de reenvío no es un nuevo y originario juicio, sino más bien una nueva fase que se vincula a la sentencia de anulación de la sentencia anterior, provocada por el recurso de casación, agregando acerca del juicio de reenvió, "se encuentra vinculado al juicio anterior a través del procedimiento impugnativo que culminó en la anulación, por tratarse de la misma causa que ha sido decidida y debe volverse a decidir con criterio integrativo complementario de la sustitución". ${ }^{65}$

En virtud de lo prescrito en el artículo 386 del Código Procesal Penal el juicio de reenvío no se podría entender como independiente del juicio anulado, ya que la Corte respectiva al anular una sentencia y el juicio oral que ella resuelve debe determinar el estado en que debe quedar el procedimiento. La ley faculta a la Corte respectiva para retrotraer el procedimiento hasta etapas iníciales tales como la etapa de investigación. ${ }^{66}$ Lo descrito podría llevar a una nueva audiencia de preparación de juicio oral, en la cual la prueba admitida difiera de la prueba que se admitió para ser conocida en el primer juicio oral. La situación anterior, claramente hace que el juicio de reenvió pueda estar intensamente determinado por lo resuelto por el recurso de nulidad y estar entonces determinado por lo resuelto en el recurso. ${ }^{67}$

\footnotetext{
${ }^{64}$ DE LA RUA, Fernando, Teoría General del Proceso, Buenos Aires: Ediciones DePalma, 1991, p. 280.

${ }^{65}$ Citado por CAFFERATA NORES, José, "La Prohibición de la Reformatio in Peius en el juicio de reenvío", en: DEL MISMO (Comp.), Eficiencia del Sistema Penal y Garantías Procesales, ¿Contradicción o Equilibrio?, Córdova: Editorial Mediterránea, 2000, p. 89.

${ }^{66}$ Al respecto en sentencia de nulidad C. Sup., rol 3198-08 de fecha 13/08/08 en que se retrotrae en los siguientes términos: "restableciéndose el procedimiento al estado de citar a los intervinientes para la realización de una nueva audiencia preparatoria de juicio oral, por juez no inhabilitado, y cumplir las etapas procesales posteriores conforme a derecho, en todas las cuales la imputada deberá ser representada debidamente por abogado habilitado para el ejercicio de la profesión". En los mismos términos sentencias de nulidad C. Sup. rol 6175-2008 de fecha 26/11/08., rol 4954-08 de fecha 12/11/08, rol: 6934-09 de fecha 23/12/09 y rol: 4.954-08 de fecha 12/11/08. Por último, en sentencia de nulidad C. Sup rol: 1314-10 de fecha 05/05/2010 se retrotrae hasta la etapa de investigación.

67 Así en sentencia de nulidad C. Sup rol 9758-09. de fecha 13/04/2010 en su considerando 23 la Excelentísima Corte Suprema al acoger el recurso de nulidad retrotrae hasta el juicio oral pero excluyendo prueba: “.. SE ACOGE el recurso de ...se declara que se anula tanto dicho fallo como el juicio oral de que es objeto bajo el ..., debiendo la causa retrotraerse al estado de celebrarse uno nuevo ante el Tribunal Oral en lo Penal competente y no inhabilitado que corresponda, excluyéndose de su conocimiento toda referencia respecto de los antecedentes obtenidos de la declaración tomada por la Policía de Investigaciones al imputado...". En los mismos términos sentencias de nulidad C. Sup. Rol: 6305-10 de fecha 19/10/10 y C Sup rol: 4001-10. de fecha 24/08/2010.
} 


\section{Polit. crim. Vol. 6, No 12 (Diciembre 2011), Art. 6, pp. 448 - 473. [http://www.politicacriminal.cl/Vol_06/n_12/Vol6N12A6.pdf]}

Otra situación que es necesaria analizar para entender los efectos del recurso de nulidad en el Código Procesal Penal, es la que se produce cuando una sentencia condenatoria es recurrida sólo por quien resulta condenado. A saber, si en un juicio oral existen dos acusados y uno de ellos resulta condenado y el otro absuelto; y el primero de ellos recurre del fallo para ser conocido por la Ilustrísima Corte de Apelaciones respectiva, la cual para el caso de acogerlo y ordenar un nuevo juicio oral, deberá ordenar un nuevo juicio oral sólo respecto del imputado originalmente condenado y no contra el absuelto.

Como se observa, entonces, la resolución dictada por la Ilustrísima Corte de Apelaciones respectiva, mantiene vigente el fallo del Tribunal Oral para los efectos del acusado absuelto y nulo el mismo fallo para el acusado condenado por el Tribunal Oral. ${ }^{68}$

En síntesis, como se puede concluir, la doctrina procesal está conteste en el concepto de nulidad parcial, lo que significa que al acogerse un recurso de nulidad parte del fallo se anula y otra parte del mismo permanece vigente. Asimismo, en nuestro sistema una resolución que es anulada puede permanecer vigente a pesar de la nulidad para los efectos de la absolución, como es el caso del proceso en que se juzga a dos personas o una sola y se acoge la nulidad, ya sea por uno de los dos sometidos a juicio, o sólo por un delito.

Pues bien, entonces, en este punto queda palmariamente claro que el recurso de nulidad contemplado en el Código Procesal Penal, no es lo mismo que la invalidación del acto ${ }^{69}$ y que al acogerse un recurso de nulidad lo que se declara es que la sentencia y juicio anulado son ineficaces para condenar, pero no para otros efectos legales, como en la especie es el usar lo producido en él para fines de desacreditación.

\footnotetext{
${ }^{68}$ Criterio que encuentra sustento en sentencia de la Corte Suprema Rol No 4001-10 de fecha 24/08/2010, que acogió la posibilidad de nulidad parcial según se da cuenta en el considerando $31^{\circ}$ del fallo citado: "Que, finalmente, cabe dejar constancia que el Ministerio Público no impugnó la sentencia en aquella parte que absolvió a ...,... y ...., por lo que, tal como lo reconoció expresamente en estrados el representante del ente persecutor al inicio del debate, para el evento de acogerse los recursos de nulidad interpuestos, ello no importa afectar la situación de los ya absueltos, a cuyo respecto tampoco recurrió, citándose como fundamento lo dispuesto en el artículo 360 del Código Procesal Penal, según el cual en esa parte el veredicto quedó firme o ejecutoriado.". Al respecto consulta recurso de queja ante la Corte Suprema de fecha 30/09/2010 rol $4972-10$ en que nuestra Excelentísima Corte Suprema acoge una queja en contra de la segunda sala de la Ilustrísima Corte de Apelaciones de Valdivia en atención a que ésta había invalidado una sentencia y ordenado un nuevo juicio más allá de lo prescrito en el artículo 360 del Código Procesal Penal invocando la segunda sala de la Ilustrísima Corte de Apelaciones de Valdivia que: “...En la resolución, se indicó que no obstante haberse acogido parcialmente la nulidad interpuesta, de conformidad al artículo 386 del Código Procesal Penal, sus efectos son absolutos tanto del juicio oral y de la sentencia, lo que afecta a todos los intervinientes.", lo que fue invalidada por vía de recurso de queja por la Excelentísima Corte Suprema. Anteriormente, nuestra Excelentísima Corte Suprema en sentencia de fecha 07/01/08 causa Rol N ${ }^{\circ}$ 5325-07, conociendo de un recurso de queja interpuesto por el Ministerio Público en contra de los Ministros de la Ilustrísima Corte de Apelaciones de Santiago, por haber acogido un recurso de nulidad interpuesto por una imputada condenada por un delito y absuelta por otro en la realización de un mismo juicio oral, recurso de nulidad C. Stgo., de fecha 28/09/07 Rol No 1969-2.007, resolvieron ordenar un nuevo juicio oral por Tribunal no inhabilitado sólo por el delito en que la acusada había sido condena, resolución en que la Excelentísima Corte Suprema rechazó el recurso de queja deducido en contra de los Ministros de la Corte de Apelaciones de Santiago.

${ }^{69}$ En este mismo sentido CAFFERATA NORES, “La Prohibición”, cit. nota n ${ }^{\circ} 65$ p. 90, señala citando a diversos autores que la sentencia “...la sentencia anulada, a pesar de la anulación, conserva ese "efecto remanente" que la minoría de la corte le niega.".
} 
VIAL, Pelayo. "El derecho a confrontación con declaraciones de un juicio anulado en el marco del proceso penal".

\section{Acerca de los límites de la desacreditación.}

Como se señaló el contraexamen materializa el principio de contradicción. Este último principio en doctrina se entiende como parte integrante del derecho a defensa ${ }^{70}$ y a su vez del debido proceso como un derecho general de las partes. ${ }^{71}$ Una vez abandonado el sistema inquisitivo, entendiendo por proceso el enfrentamiento entre partes en igualdad de derechos ante un tercero imparcial, y con procedimientos civiles que deben respetar la cláusula del debido proceso, ${ }^{72}$ en los cuales el juicio debe ser a lo menos, público oral y contradictorio, ${ }^{73}$ este principio tiene pleno desarrollo.

El principio a contradicción implica que las partes tengan la posibilidad de ser oídas, ingresar pruebas, controlando la actividad jurisdiccional y de la contraria y refutar argumentos que puedan perjudicarlas. Se parte de considerar la contradicción entre partes como el más eficaz instrumento técnico para garantizar la exacta aplicación del derecho objetivo, ${ }^{74}$ se entiende que este derecho corresponde a todas las partes que tienen derecho a ser oídas, tiene una vida independiente, ya que sólo existe proceso cuando dos parte se enfrentan ante un tercero imparcial. En este estadio es necesario destacar que el mecanismo legal que asegura la contradicción es el contraexamen, ${ }^{75}$ con todas sus etapas entre las

\footnotetext{
${ }^{70}$ Parte de la doctrina vincula el derecho a contradicción con el derecho a ser oído y tiene su sustento legal en orden constitucional $\mathrm{y}$ en tratados internacionales ratificados por Chile. El contenido del derecho a contradicción estaría otorgado por el Art. 8 Ap. 2 letra f) del Pacto de San José de Costa Rica que señala: "derecho de la defensa de interrogar a los testigos presentes en el tribunal.." como asimismo en el Pacto Internacional de Derechos Civiles y Políticos art. 14 ap. 3 letra e) "a interrogar a hacer interrogar a los testigos de cargo...", ambos preceptos incorporados a nuestro derecho según lo prescrito en el artículo $5^{\circ}$ inciso $2^{\circ}$ de la Constitución Política de la República. ver LOPEZ/HORVITZ, Derecho Procesal, T. I., cit. nota $\mathrm{n}^{\circ} 45$, p. 231, citando a Julio Maier.

71 MONTERO AROCA, Juan, "La Garantía Procesal Penal y El Principio Acusatorio", La Ley: Revista jurídica española de doctrina, jurisprudencia y bibliografía $\mathrm{N}^{\circ} 1$ (1994), pp. 973-984 señala: "Si el principio acusatorio atiende a la situación de imparcialidad del juzgador, el de contradicción se refiere a las partes y es algo tan viejo como lo que está implícito en el brocardo "nadie puede ser condenado sin ser oído", lo que se resuelve básicamente en un derecho fundamental de todas las partes, de acusadores y acusados, que a tiende a: la necesidad de ser oído, que en el proceso penal no puede calificarse de derecho renunciable. Si para el ministerio público el ejercicio de la acción penal es un deber, una vez que se produce su ejercicio, la necesidad de que se le oiga es un derecho irrenunciable...". También DAMASKA, "The Uncertain Fate", cit. nota $\mathrm{n}^{\circ}$ 20, p. 846, señala al principio de contradicción como autónomo: "El "principio llamado de contradicción" debe entregar a cada parte la oportunidad de contradecir el material de hecho producido por el adversario en algún momento del curso del proceso". Traducción libre de: "The so-called "principle of contradiction" audi et, enough to give each party an opportunity to contradict the factual material produced by adversary at some time in the course of proceeding".

${ }^{72}$ Ver Proyecto Código Procesal Civil, art $2^{\circ}$, "Debido proceso de ley y procedimiento".

${ }^{73}$ DUCE/RIEGO/MARIN, "Reforma a los Procesos", cit. nota n 41, p. 35.

${ }^{74}$ MONTERO AROCA, "Principio Acusatorio y Prueba", cit. nota ${ }^{\circ} 42$, p. 40.

${ }^{75}$ En recurso de nulidad C. Sup. Rol 2345-05 de fecha 13/07/05 se ha señalado los alcances del contraexamen: "QUINTO: Que, en otro orden de ideas, el sentenciador incurre en un error al suponer que el derecho de defensa del imputado se salvaguarda simplemente con la facultad que tiene para contrainterrogar a los testigos del querellante en la audiencia de estilo. Su derecho a defensa pasa también por tener la oportunidad y tiempo suficiente para su debida preparación. A este respecto es pertinente traer a colación que el artículo 309 del Código Procesal Penal -aplicable aquí en virtud de lo que dispone el artículo 389 del mismo cuerpo legal-, sin perjuicio de declarar que en el procedimiento penal no existen testigos inhábiles, dispone que los intervinientes pueden "dirigir al testigo, preguntas tendientes a demostrar su credibilidad o falta de ella, la existencia de vínculos con alguno de los intervinientes que afectaren o pudieren afectar su
} 
Polit. crim. Vol. 6, № 12 (Diciembre 2011), Art. 6, pp. 448 - 473.

[http://www.politicacriminal.cl/Vol_06/n_12/Vol6N12A6.pdf]

cuales está la desacreditación, de limitarse esta última se limita el principio de contradicción integrante del debido proceso y principio estructural para esta frente a un verdadero proceso.

\subsection{Uso de prueba para fines de impugnación y no como prueba sustantiva.}

A saber, es diferente que determinado material probatorio sea usado como prueba sustantiva de cargo o descargo, que ese mismo material probatorio sea usado sólo con fines de impugnación. Al respecto dos situaciones desarrolladas en el derecho probatorio de EE. UU. nos ayudan a clarificar la diferencia.

La prohibición del uso de prueba de referencia, está fundada en consideraciones intrínsecas al propósito del derecho probatorio, esto es, la búsqueda de la verdad de los hechos, ${ }^{76}$ y tiene por objeto asegurar evidencia confiable en los procesos. En doctrina se estima que para que la prueba testimonial sea confiable debe reunir tres requisitos: (i) El testigo debe tener conocimiento personal sobre lo que declara, (ii) Estar juramentado y (iii) Debe ser contraexaminado para descubrir cualquier debilidad en su relato. ${ }^{77}$

Pues bien, la prohibición en contra del uso de prueba de referencia evita que se reciba en juicio una declaración que se hizo fuera de éste, la que se ofrece para probar que tal declaración es verdadera, la prohibición, anterior no es aplicable cuando ella es utilizada para fines de impugnación.

A saber, cuando se usa prueba de referencia -como una declaración prestada en notaria público sobre los mismos hechos declarados en juicio- ya no para probar que lo aseverado en ella es verdadero, si no que para impugnar al testigo demostrando que éste en otra declaración formal sobre los mismos hechos declaro algo distinto, la prueba de referencia es permitida. A mayor abundamiento entonces, la declaración prestada fuera del juicio, no podría ser utilizada para probar la veracidad de su contenido, ya que podría ser considerada prueba de referencia e inadmisible, ${ }^{78}$ pero si para fines impugnatorios.

Otra situación interesante de analizar es la impugnación mediante evidencia ilegalmente obtenida. En Walder v. US, el acusado declaró que nunca había usado drogas y el ministerio público presento pruebas de posesión de heroína de un caso seguido en su contra en que la heroína había sido excluida por haber sido obtenida en forma ilegal. La Corte Suprema permitió la presentación de la prueba previamente excluida argumentando que la regla no puede ser usada para permitir perjurio. ${ }^{79}$ En United States v. Havens, ${ }^{80}$ se permitió

imparcialidad, o algún otro defecto de idoneidad, derecho que sólo podrá ejercer después de averiguar con anticipación todo cuanto concierna al testigo propuesto una vez que conozca con precisión su identidad y halla previsto las preguntas que le podrá formular en el juicio.".

${ }^{76}$ CHIESA, Tratado de Derecho Probatorio, T. II, cit. nota ${ }^{\circ}$ 51, p. 565.

${ }_{78}^{77}$ MAUET/WOLFSON, Trial Evidence, cit. nota ${ }^{\circ} 19$, p. 133.

${ }^{78}$ Hearsay Rule FRE 801 y siguientes.

${ }^{79}$ U.S. Supreme Court, Walder v. United States, 347 U.S. 62 (1954) "Held: Petitioner's assertion on direct examination that he had never possessed any narcotics. Opened the door, solely for the purpose of attacking petitioner's credibility, to evidence of the heroin unlawfully seized in connection with the earlier proceeding. Take the present situation. Of his own accord, the defendant went beyond a mere denial of complicity in the 
VIAL, Pelayo. "El derecho a confrontación con declaraciones de un juicio anulado en el marco del proceso penal".

usar prueba excluida en contra del acusado pero sólo la referente a la falsedad de lo declarado previamente. Por último, en James v. Illinois, no se permitió el uso de pruebas excluidas para desacreditar testigos. ${ }^{81}$

En suma, en el sistema de EE. UU. bajo la IV enmienda se puede utilizar evidencia ilegalmente obtenida para impugnar lo declarado por el acusado -ya sea en examen directo o en contrainterrogatorio- pero no para impugnar a otros testigos de la defensa. ${ }^{82}$

Respecto a la prueba obtenida en violación de la $\mathrm{V}$ enmienda esta puede ser utilizada para fines desacreditatorios siempre que se trate de declaraciones libres, que no sean producto de coacción policial, si en la declaración medió coacción no es admisible bajo figura alguna.

Pero volviendo al objeto de lo estudiado en el presente trabajo, el uso de declaraciones prestadas durante un juicio anulado no revive esas declaraciones para probar que lo ahí declarado es verdadero, sólo se utilizan para poder graficar que ante una instancia formal el testigo declaró algo distinto sobre los mismo hechos, lo que es suficiente para atacar su credibilidad.

\section{Conclusiones.}

Previo establecer la conclusión al tema propuesto en el presente trabajo debemos analizar una última situación. El artículo 387 inc. $2^{\circ}$ del Código Procesal Penal prohíbe recurrir un segundo juicio oral condenatorio en el evento que el primero de ellos también hubiera

crimes of which he was charged and made the sweeping claim that he had never dealt in or possessed any narcotics. Of course, the Constitution guarantees a defendant the fullest opportunity to meet the accusation against him. He must be free to deny all the elements of the case against him without thereby giving leave to the Government to introduce by way of rebuttal evidence illegally secured by it, and therefore not available for its case in chief. Beyond that, however, there is hardly justification for letting the defendant affirmatively resort to perjuries testimony in reliance on the Government's disability to challenge his credibility".

${ }^{80}$ U.S. Supreme Court, United States v. Havens, 446 U.S. 620 (1980), "Held: A defendant's statements made in response to proper cross-examination reasonably suggested by the defendant's direct examination are subject to otherwise proper impeachment by the Government, albeit by evidence that has been illegally obtained and is inadmissible as substantive evidence of guilt(...). Here, respondent's testimony on direct examination could easily be understood as a denial of any connection with McLeroth's T-shirt and as a contradiction of McLeroth's testimony, and the Government on cross-examination reasonably called attention to respondent's answers on direct and then asked whether he had anything to do with sewing the pockets on McLeroth's T-shirt. This was cross-examination growing out of respondent's direct testimony, and the ensuing impeachment did not violate his constitutional rights.".

${ }^{81}$ U.S. Supreme Court, James v. Illinois, 493 U.S. 307 (1990) "Sostenido: La Corte Suprema Estatal se equivoca extendiendo la excepción de desacreditación abarcando a todos los testimonio de los testigos de la defensa. Tal expansión frustraría los propósitos que están subyacen en la regla de exclusión. La racional búsqueda de la verdad que apoya la desacreditación del acusado no se aplica con igual la fuerza de otros testigos". Traducción libre y sólo referencial de: "Held: The State Supreme Court erred in expanding the impeachment exception to encompass the testimony of all defense witnesses. Such expansion would frustrate rather than further the purposes underlying the exclusionary rule. The truth-seeking rationale supporting the impeachment of defendants does not apply with equal force to other witnesses".

${ }^{82}$ CHIESA, Tratado de Derecho Probatorio, T. I, cit. nota ${ }^{\circ}$ 51, p. 402. 


\section{Polit. crim. Vol. 6, № 12 (Diciembre 2011), Art. 6, pp. 448 - 473. [http://www.politicacriminal.cl/Vol_06/n_12/Vol6N12A6.pdf]}

resultado en condena, ${ }^{83}$ lo que parte de la doctrina criticó y advirtiendo sobre su inconstitucionalidad. ${ }^{84}$ La norma anterior fue declarada constitucional por el Tribunal Constitucional mediante sentencia de fecha 7 de octubre de 2008, la que esbozó la posibilidad que ante la situación descrita sería procedente el recurso de queja. ${ }^{85}$ De aceptarse la posición sustentada por algunos Tribunales Orales en lo Penal de impedir desacreditar a un testigo con lo declarado en un primero juicio anulado y no existir motivos

${ }^{83}$ Recurso de nulidad de fecha 18/03/2008, rol 6181-07:“2 Que en el presente caso, el acusado Aarón David Vásquez Muñoz, en el primer juicio criminal, resultó condenado a purgar una sanción de tres años de internación en régimen semicerrado con programa de reinserción social, como autor del homicidio simple de Alejandro Inostroza Villarroel. Más tarde, anulado que fue dicho veredicto, por sentencia de 30 de octubre de 2007 fue nuevamente condenado, pero esta vez a cumplir una condena de siete años de internación en régimen cerrado con programa de reinserción social por su responsabilidad como autor, ahora, en el delito de homicidio calificado de Alejandro Inostroza Villarroel. $3^{\circ}$ Que, como puede verse, la situación sometida al conocimiento de este tribunal no se ajusta al caso de excepción antes referido, toda vez que tanto la sentencia recaída en el primer juicio -que fue anulada- como la dictada en el segundo juicio -y que es ahora objeto de impugnación- fueron condenatorias para el acusado Aarón Vásquez Muñoz, siendo de advertir que la norma respectiva no distingue si se trata de partes, capítulos o acápites del fallo los que deban ser estimados absolutorios o condenatorios o si deba comprenderse la extensión o naturaleza de la pena impuesta, o tal vez, la diferente calificación que el tribunal haya dado al delito o a sus circunstancias. En estas condiciones, de acuerdo a lo prevenido en el artículo citado y teniendo presente, además, lo decidido por el Tribunal Constitucional en sentencia de treinta de enero del año en curso, cuya copia rola a fs. 383 y siguientes de autos, se declara inadmisible el recurso de nulidad ...".

${ }^{84}$ LÓPEZ/HORVITZ, Derecho Procesal, T. II, cit. nota n ${ }^{\circ} 45$, p. 446, señalan: "La norma en cuestión debiera, entonces ser ajustada cuanto antes para satisfacer los estándares impuestos por nuestra Constitución y tratados internacionales sobre derechos humanos, que reconocen siempre y en todo caso el derecho a recurrir en contra de una sentencia condenatoria. Mientras esa modificación no se haga, sólo cabe considerar la disposición de la primera parte del inciso $2^{\circ}$ del art. 387 CPP, como una disposición que debe ser declarada inaplicable por inconstitucional". Los autores además citan a los profesores Cristián Maturana Miquel y Alex Carocca Pérez, que opinan en el mismo sentido.

${ }^{85}$ Sentencia T. Const. de fecha 7/10/08, Rol 1130-07-INA, el que se refirió a la constitucionalidad del inciso $2^{\circ}$ del artículo 387 del Código Procesal Penal, rechaza en voto de mayoría declararlo inaplicable, pero en el considerando duodécimo señalan expresamente que la sentencia definitiva dictada en un segundo juicio oral a consecuencia de la resolución que hubiera acogido el recurso de nulidad deducido en contra de un primer juicio oral condenatorio puede ser susceptible de recurso de queja: "DECIMOSEGUNDO.- Que, a modo de conclusión, la apelación deja de ser el medio ordinario de impugnación de sentencias definitivas en materia penal, las que en el nuevo sistema son de única instancia, pasando el recurso de nulidad de los artículos 372 y siguientes a ser el único medio para impugnar las sentencias de los tribunales penales, sin perjuicio de las acciones de fuente constitucional que eventualmente pudieren ser procedentes, como, por ejemplo, el recurso de queja, según lo señalado por esta Magistratura en la sentencia del proceso Rol $\mathrm{N}^{\circ}$ 986. En términos procesales, se elimina un recurso cuyo fundamento era el agravio y se mantiene el vicio como sustento del recurso de nulidad. En efecto, cabe tener presente que, en abstracto, el mismo Código Procesal Penal ha establecido en sus artículos 473 y siguientes la revisión de sentencias firmes y que el artículo 545 del Código Orgánico de Tribunales establece el recurso de queja para los casos en que exista falta o abuso que no sea subsanable por otra vía y no exista recurso de otro tipo. En dicha situación cabe concluir que resultaría plenamente procedente el recurso de queja previsto en el artículo 545 del Código Orgánico de Tribunales, desde que dicha vía de impugnación es factible respecto de las faltas o abusos graves cometidos en la dictación de resoluciones de carácter jurisdiccional, en la especie, sentencia definitiva condenatoria y respecto de la cual no procede recurso alguno, lo que ha sido desarrollado por esta Magistratura en la ya citada sentencia del proceso rol No $986 ; ”$;. 
VIAL, Pelayo. "El derecho a confrontación con declaraciones de un juicio anulado en el marco del proceso penal".

para deducir un recurso de queja, nos podría llevar a decisiones injustas producto de una condena basada en testimonios falsos sin posibilidad de ser recurrida. ${ }^{86}$

A efectos de evitar tan nefastas consecuencias, es que debemos estar atentos a la advertencia del profesor Mirjan Damaska acerca del incierto destino que puede tener el traspasar instituciones o formas de aproximarse a la prueba entre el sistema anglosajón y el continental sin evaluar que esas formas procesales están insertas en cada sistema en un conjunto o contexto que las hacen efectivas. ${ }^{87}$ Es hora entonces de ir más allá del mero análisis cuantitativo de nuestra reforma procesal penal y avanzar a su análisis sustantivo, evaluando si las nuevas instituciones han sido debidamente desarrolladas y cumplen sus objetivos en el sistema.

La solución para el tema propuesto, en mi opinión pasa por entender que la nulidad es un concepto o categoría jurídico, representativo de la declaración de invalidez de un acto para producir ciertos efectos jurídicos, $\mathrm{y}$, por ende, no predica ni significa la inexistencia del acto (categoría perteneciente a otro mundo), como si en él no se hubiera realizado. ${ }^{88}$ En el sentido propuesto y para el tema que convoca este trabajo, no es lo mismo usar material proveniente de un juicio anulado para efectos de desacreditar a un testigo o perito que usar ese mismo material como elemento probatorio de cargo o descargo para probar hechos pertenecientes a las posiciones de defensa o de sustentar la acción penal.

Como se ve el contraexamen requiere mayor desarrollo entre nosotros, conforme a todas sus etapas y derechos consagrados a los litigantes, tales como el demostrar la falta de credibilidad, vínculos, perjuicio o idoneidad, de un testigo mediante el proceso de impugnación, sin limitar el uso de material al efecto para cumplir su verdadero rol en un juicio oral de corte adversarial.

Lo anterior, es una tarea compleja toda vez que la normativa existente tanto legal, como a nivel de tratados es escasa y requiere de interpretaciones conforme al concepto de debido proceso y a la estructura básica de éste: su adversariedad.

Finalmente y una vez comprendido que el nuevo sistema procesal penal entregó al contraexamen entre otras la difícil misión de ser el primer paso para establecer la verdad de lo declarado por un testigo, procede que avancemos hacia el desarrollo de éste en todas sus fases para lograr convertirlo en un verdadero filtro de la evidencia que consagre pruebas más confiables que los mecanismos contenidos en el viejo código de procedimiento penal, respecto a la depuración de la evidencia y no generar un sistema desmejorado que no permita acercarnos a la verdad de los declarado por los declarantes.

\footnotetext{
86 Sobre la preocupación para el caso que la ley correctamente aplicada produzca injusticias véase ROBINSON, Paul H. y CAHILL, Michael T., Law Without Justice, Why Criminal Law Doesn't Give People What They Deserve, New York: Oxford University Press, 2006.

${ }^{87}$ DAMASKA, "The Uncertain Fate", cit. nota n 20, p. 851.

${ }^{88}$ MAIER, Función Normativa de la Nulidad, cit. nota $\mathrm{n}^{\circ} 63$, p. 141. El autor señala que lo que se quiere significar con la nulidad es que el acto carece de ciertos efectos que tuvo en mira quien lo realizó, pero este no desaparece pese a la declaración de nulidad.
} 
Polit. crim. Vol. 6, № 12 (Diciembre 2011), Art. 6, pp. 448 - 473.

[http://www.politicacriminal.cl/Vol_06/n_12/Vol6N12A6.pdf]

\section{BIBLIOGRAFÍA}

AROCENA, Gustavo A., La nulidad en el proceso penal, Argentina: Editorial Mediterránea, 2002.

BARRIENTOS PARDO, Ignacio, "Prohibición de la reforma in peius y la realización de Nuevo Juicio", Revista de Estudios de la Justicia No 9 (2007).

BOVINO, Alberto, "Juicio y Verdad en el Procedimiento Penal", en: AA. VV. Estudios sobre Justicia Penal, libro homenaje al profesor Julio Maier, Buenos Aires: Editoriales del Puerto, 2005.

, "Ingeniería de la Verdad. Procedimiento Penal Comparado", artículo publicado en http://derechopenalonline.com

BOYLL, Jeffrey A., "Witness Explanations During Cross-Examination: a Rule of Evidence Examined", Indiana Law Journal (spring 1982).

CAFFERATA NORES, José, "La Prohibición de la Reformatio in Peius en el juicio de reenvio", en: DEL MISMO (Comp.), Eficiencia del Sistema Penal y Garantías Procesales, ¿Contradicción o Equilibrio?, Córdova: Editorial Mediterránea, 2000.

CAROCA, Alex, "Recuperación de la Importancia de la Prueba en un Modelo Procesal Civil Oral" en: ANDRÉS DE LA OLIVA SANTOS y DIEGO PALOMO VÉLEZ (coords.), Proceso Civil, Hacia una Nueva Justicia Civil, Santiago: Editorial Jurídica de Chile, 2007.

CHIESA, Ernesto L., Tratado de Derecho Probatorio, EE.UU.: Publicaciones JTS, Reimpresión, 2005.

DAMASKA, Mirjan, "The Uncertain Fate of Evidentiary Transplants: Anglo-American and Continental Experiments", The American Journal of Comparative Law Vol. 45, N4 (otoño 1997).

"Presentation of Evidence and Fact-Finding Precision", University of Pennsylvania Law Review, Vol. 123.

, "Truth \& Its Rivals: Evidence Reform and the Goals of Evidence Law", University of California, Hastings College of Law Hasting Law Journal (January 1998).

DE LA RUA, Fernando, Teoría General del Proceso, Buenos Aires: Ediciones DePalma, 1991.

DUCE, Mauricio, RIEGO, Cristian y MARÍN, Felipe, "Reforma a los Procesos Civiles Orales: Consideraciones desde el debido proceso y calidad de información”, en CABEZÓN P., Andrea (Coord.) Justicia Civil: Perspectiva para una Reforma en América Latina, Santiago: CEJA, 2008.

IBADE EROSTARDE, Izaskun, Psicología del Testimonio, España: Erein Editoriales, 2004.

KENNEDY, Jerome P., "Writing the wrongs: The role of defence counsel in wrongful convictions A commentary", Canadian Journal of Criminology and Criminal Justice/La Revue canadienne de criminologie et de justice pénale v.46, n. 2 (2004).

LaFAVE, Wayne R., ISRAEL, Jerold H. y KING, Nancy J., Criminal Procedure, St. Paul: Thomson West, $4^{\text {a }}$ ed., 1999.

LANGBEIN, John H., The Origins of Adversary Criminal Trial, EE.UU.: Oxford University Press, 2005. 
VIAL, Pelayo. "El derecho a confrontación con declaraciones de un juicio anulado en el marco del proceso penal".

LOFTUS, Elizabeth F., Eyewitness Testimony, Boston: Harvard University Press, $4^{\mathrm{a}}$ ed., 2002.

MACCARTHY, Terence F., MacCarthy on Cross-Examination, Chicago: American Bar Association, 2007.

MAIER, Julio, Derecho Procesal Penal, Buenos Aires: Editores del Puerto s.r.1., 2002.

, Función Normativa de la Nulidad, Buenos Aires: Ediciones DePalma, 1980.

MATURANA MIQUEL, Cristian, Los Medios de Prueba, separata de la Universidad de Chile, Facultad de Derecho, año 1996.

MAUET, Thomas y WOLFSON, Warren D., Trial Evidence, EE.UU.: Aspen Publishers, $3^{\mathrm{a}}$ ed., 2005.

MONTERO AROCA, Juan, "Prueba y Proceso Penal", en: GÓMEZ COLOMER, Juan Luis (coord.), Principio Acusatorio y Prueba en el Proceso Penal. Inutilidad Jurídica de un eslogan politico", Valencia: Tirant lo Blanch, 2008.

, "La Garantía Procesal Penal y El Principio Acusatorio", La Ley: Revista jurídica española de doctrina, jurisprudencia y bibliografía $\mathrm{N}^{\circ} 1$ (1994).

NOGUEIRA ALCALA, Humberto, El debido proceso en la Constitución y el Sistema Interamericano, Santiago: Editorial Librotecnia, 2007.

PALOMO VÉLEZ, Diego, “Proceso Civil Oral ¿Qué modelo de Juez Requiere?”, en DEL MISMO, Reforma Procesal Civil, Santiago: Abeledo Perrot, 2010.

POZNER, Larry S. y DODD, Roger, Cross Examination Science and Techniques, Charlottesville: The Michie Company, 1993.

STRONG, John W., McCormick on Evidence, St. Paul: West Group, student edition, $5^{\mathrm{a}}$ ed., 1999.

TARUFFO, Michelle, "Investigación Judicial y Producción de Prueba por las Partes", en: VERA ALVAREZ, Nicolás (coord.), La Prueba, Artículos y Conferencias, Editorial Metropolitana, 2009. 